\title{
Two- and three-dimensional structures of the descent of mesospheric trace constituents after the 2013 sudden stratospheric warming elevated stratopause event
}

\author{
David E. Siskind ${ }^{1}$, V. Lynn Harvey ${ }^{2}$, Fabrizio Sassi ${ }^{1}$, John P. McCormack ${ }^{1, a}$, Cora E. Randall ${ }^{2,3}$, Mark E. Hervig ${ }^{4}$, \\ and Scott M. Bailey ${ }^{5}$ \\ ${ }^{1}$ Space Science Division, Naval Research Laboratory, Washington DC, USA \\ ${ }^{2}$ Laboratory for Atmospheric and Space Physics, University of Colorado, Boulder CO, USA \\ ${ }^{3}$ Department of Atmospheric and Oceanic Sciences, University of Colorado, Boulder CO, USA \\ ${ }^{4}$ GATS Inc., Driggs ID, USA \\ ${ }^{5}$ Bradley Department of Electrical and Computer Engineering, Virginia Tech, Blacksburg VA, USA \\ ${ }^{a}$ now at: Heliophysics Division, National Aeronautics and Space Administration, Washington DC, USA
}

Correspondence: David E. Siskind (david.siskind@nrl.navy.mil)

Received: 22 January 2021 - Discussion started: 27 January 2021

Revised: 22 July 2021 - Accepted: 25 July 2021 - Published: 22 September 2021

\begin{abstract}
We use the Specified Dynamics version of the Whole Atmosphere Community Climate Model Extended (SD-WACCMX) to model the descent of nitric oxide (NO) and other mesospheric tracers in the extended, elevated stratopause phase of the 2013 sudden stratospheric warming (SSW). The dynamics are specified with a high-altitude version of the Navy Global Environmental Model (NAVGEMHA). Consistent with our earlier published results, we find that using a high-altitude meteorological analysis to nudge WACCMX allows for a realistic simulation of the descent of lower-thermospheric nitric oxide down to the lower mesosphere, near $60 \mathrm{~km}$. This is important because these simulations only included auroral electrons and did not consider additional sources of NO from higher-energy particles that might directly produce ionization, and hence nitric oxide, below $80-85 \mathrm{~km}$. This suggests that the so-called energetic particle precipitation indirect effect (EPP-IE) can be accurately simulated, at least in years of low geomagnetic activity, such as 2013, without the need for additional NO production, provided the meteorology is accurately constrained. Despite the general success of WACCMX in bringing uppermesospheric NO down to 55-60 km, a detailed comparison of the WACCMX fields with the analyzed NAVGEMHA $\mathrm{H}_{2} \mathrm{O}$ and satellite $\mathrm{NO}$ and $\mathrm{H}_{2} \mathrm{O}$ data from the Solar Occultation for Ice Experiment (SOFIE) and the Atmo-
\end{abstract}

spheric Chemistry Experiment-Fourier Transform Spectrometer (ACE-FTS) reveals significant differences in the latitudinal and longitudinal distributions at lower altitudes. This stems from the tendency for WACCMX descent to maximize at sub-polar latitudes, and while such sub-polar descent is seen in the NAVGEM-HA analysis, it is more transient than in the WACCMX simulation. These differences are linked to differences in the transformed Eulerian mean (TEM) circulation between NAVGEM-HA and WACCMX, most likely arising from differences in how gravity wave forcing is represented. To attempt to compensate for the differing distributions of model vs. observed NO and to enable us to quantify the total amount of upper-atmospheric NO delivered to the stratopause region, we use potential vorticity and equivalent latitude coordinates. Preliminary results suggest both model and observations are generally consistent with $\mathrm{NO}$ totals in the range of $0.1-0.25$ gigamoles $(\mathrm{GM})$.

\section{Introduction}

One of the more interesting and challenging problems in middle-atmospheric science has been to accurately represent the descent of upper-mesospheric and thermospheric nitric oxide (NO) down to the stratopause and below dur- 
ing polar winter conditions. The idea is that since NO is copiously produced in the lower thermosphere by auroral and photo-electrons (Gerard and Barth, 1977; Barth et al., 1988; Siskind et al., 1989, 1990), if some fraction of this NO were to be transported to the middle atmosphere, it could play a role in the stratospheric ozone budget (Langematz and Tully, 2018). This would signify that energetic electron precipitation (EEP) in the upper atmosphere could affect middle-atmospheric (and possibly lower-atmospheric) (Seppala et al., 2009) chemistry and climate. That such upperto middle-atmospheric coupling might occur was proposed many years ago by Solomon et al. (1982). They noted that the most likely place for this to occur would be in the winter polar regions where the mean circulation favors descent and also where photolysis would naturally be weak. Observational validation of this idea remained limited (although see Russell et al., 1984) until, starting in the mid-1990s, observations of NO (Siskind and Russell, 1996; Siskind et al., 2000), $\mathrm{NO}_{2}$ (Randall et al., 1998), and total odd nitrogen $\left(\mathrm{NO}_{y}\right)$ (Rinsland et al., 1999) provided evidence for the presence of upper-atmospheric odd nitrogen at stratospheric altitudes. Since those early results, several other datasets, including the Michelson Interferometer for Passive Atmospheric Sounding (MIPAS) (Funke et al., 2005, 2014), the Scanning Imaging Absorption Spectrometer for Atmospheric Cartography (SCIAMACHY) (Sinnhuber et al., 2016), the Atmospheric Chemistry Experiment Fourier Transform Spectrometer (Bernath et al., 2005) (ACE-FTS, hereinafter just ACE) (Randall et al., 2007), the submillimeter radiometer (SMR) on the ODIN satellite (Perot et al., 2014), the Solar Occultation for Ice Experiment (SOFIE) on the Aeronomy of Ice in the Mesosphere (AIM) explorer (Bailey et al., 2014), and the Ozone Monitoring Instrument (OMI) on the NASA AURA satellite (Gordon et al., 2020) have contributed observations of this mechanism of thermosphere-middle atmosphere coupling.

The transport of thermospheric $\mathrm{NO}_{x}$ to the stratosphere is manifested quite differently in the Northern Hemisphere (NH) and Southern Hemisphere (SH). In the south, due to relatively quiescent middle-atmosphere dynamics, it is a regular occurrence, and upper-stratospheric $\mathrm{NO}_{x}$ is seen to vary in accordance with geomagnetic activity (Siskind et al., 2000; Randall et al., 2007; Funke et al., 2014a; Gordon et al., 2020). By contrast, in the more dynamically active $\mathrm{NH}$, this longrange vertical transport is much more episodic. Of particular interest, and the subject of this work, is the descent of uppermesospheric air that has been observed after major sudden stratospheric warmings associated with so-called elevated stratopause events. Elevated stratopause events are phenomena whereby the middle-atmospheric temperature maximum, normally situated near $50 \mathrm{~km}$, reforms at or above $80 \mathrm{~km}$ right after a sudden stratospheric warming (Manney et al., 2005; Siskind et al., 2007; Chandran et al., 2011, 2013; McLandress et al., 2013; Limpasuvan et al., 2016). This jump in stratopause elevation is followed by an extended recovery phase characterized by a marked spinup of the polar night jet, and, most importantly for the present study, the descent of air from the upper mesosphere to the $45-55 \mathrm{~km}$ region. In the past 20 years, elevated stratopause events associated with enhanced NO descent have been identified and documented in 2004, 2006, 2009, 2012, 2013, and 2019 (see Perot and Orsolini, 2021, for a summary overview). For these cases, the recovery phase has seen the presence of descending tongues of either enhanced $\mathrm{CO}$ and/or $\mathrm{NO}$, or depleted $\mathrm{H}_{2} \mathrm{O}$, dropping over $30 \mathrm{~km}$ (Randall et al., 2005a, 2006, 2009; Natarajan et al., 2004; Hauchecorne et al., 2007; Manney et al., 2005, 2008, 2009a, b; Siskind et al., 2007; Bailey et al., 2014; Perot et al., 2014; Paivarinta et al., 2016). Of course these events were not all equally intense or appropriately timed during the winter season to yield maximal NO descent (cf. discussion by Holt et al., 2013); for example, some dry mesospheric air was seen to descend after a sudden stratospheric warming (SSW) in 2010 (Straub et al., 2012), but there was no observed descent of upper-mesospheric NO (Perot et al., 2014). The 2013 event, which is the focus of this paper, was one of the strongest in terms of bringing down enhanced NO from the upper mesosphere to the upper stratosphere.

Ultimately, the challenge associated with these events is in accurately simulating this mechanism of long-range vertical coupling by whole atmosphere models. This has proven difficult. Simulations of mesospheric and lower-thermospheric (MLT) $\mathrm{NO}_{x}$ descent using the Whole Atmosphere Community Climate Model (WACCM or its extended version WACCMX) have greatly underestimated the amount of $\mathrm{NO}_{x}$. This underestimate has been reported both for the Southern Hemisphere (Pettit et al., 2019) and for the Northern Hemisphere (Randall et al., 2015; Orsolini et al., 2017). A similar deficit was also reported with the Hamburg model of Neutral and Ionized Atmosphere (HAMMONIA) (Meraner et al., 2016) when operated in a free-running mode (i.e., unconstrained by observations). A comprehensive overview of models of NO descent is given by Funke et al. (2017). They concluded that "the magnitude of the simulated NO tongue is generally underestimated by these models". This underestimate has raised questions about whether the deficiency lies in the neglect of photochemical sources from, for example, medium-energy electrons or from an incomplete specification of mesospheric dynamics. In our previous work (Siskind et al., 2015), we supported the latter hypothesis, at least in years with low geomagnetic activity. Specifically, we showed that nudging WACCM with a meteorological analysis that extended up to the upper mesosphere and which presumably provided more realistic dynamical fields yielded dramatic improvements in the representation of NO descent from the MLT to the lower mesosphere (Siskind et al., 2015). Pedatella et al. (2018) reached a similar conclusion, although their combined WACCMX-DART system still underestimated the descent.

Here, we follow up on those works to consider in more detail the ability of such a nudged model to capture this de- 
scent accurately. Our main focus is on how to characterize and quantify the delivery of MLT NO to the stratopause region, what we term the net deposition. As part of our analysis, we consider the two- and three-dimensional manifestations of the descent; most previous modeling studies have been limited to coarser averages over longitude and latitude (although see Salmi et al., 2011). In addition, our simulations, combined with other recent work in this area, have implications for the role of in situ ionization occurring below $80-85 \mathrm{~km}$ during the late winter of 2013. Section 2 below discusses the modeling approach, Sect. 3 shows daily averaged results for specific latitudes, Sect. 4 presents results as a function of both latitude and longitude, Sect. 5 attempts to quantify the deposition of MLT NO in the upper stratosphere both as observed and as simulated by WACCMX, and Sect. 6 discusses the implication of these results and provides conclusions.

\section{Model calculations}

\subsection{WACCMX}

In this paper, we use the Whole Atmosphere Community Climate Model, extended version (WACCMX; Liu et al., 2010). The domain of this model extends from the ground to about $500 \mathrm{~km}$. It is divided into 108 vertical levels such that the vertical resolution is variable around a quarter of the pressurescale height in the mesosphere and lower thermosphere; for stability and efficiency reasons the resolution asymptotes to half the local scale height in the thermosphere. WACCMX can be configured to use atmospheric specifications to constrain its meteorology (winds and temperature) from the ground to any altitude; this model configuration is referred to as Specified Dynamics (SD); see Sassi et al. (2013) for some details of the initial implementation. Note that the NO descent study of Siskind et al. (2015), to which we referred above, used WACCM, not WACCMX. More recently, McDonald et al. (2018) documented significant improvements to the representation of tidal amplitudes when 3-hourly meteorological fields from the Navy Global Environmental Model (NAVGEM-HA; see next section) are supplied to WACCMX. These are used to nudge the WACCMX winds and temperatures on a timescale of $1 \mathrm{~h}$. This short timescale ensures that not just the slowly varying fields are tied to the driving meteorology, but also the shorter variability (like tides) is representative of the meteorology. It also ensures that the dynamical features in the large-scale flow, such as, for example, the overall vortex structure, are essentially identical in both WACCMX and NAVGEM-HA. Sassi et al. (2018), using atmospheric specifications from NAVGEM-HA up to $90 \mathrm{~km}$ altitude in SD-WACCMX, showed a significant influence on the wave driving of the thermospheric circulation compared with using meteorological input only up to lower altitudes (e.g., $0-50 \mathrm{~km}$ ). The simulation used in this study is exactly the same "hybma" (hybrid data assimilation with middle-atmospheric observations) model run described in Sassi et al. (2021) that uses the NAVGEM-HA output. We note that unlike Hendrickx et al. (2018) and Orsolini et al. (2017), who studied NO transport into the upper mesosphere, our simulations use the standard eddy diffusion with Prandtl $(P r)$ number $=4$. As these authors show, using $P r=2$ (lower $P r$ increases the tracer diffusion) would lead to more rapid transport into the upper mesosphere. Specifically, Hendrickx et al. (2018) showed that over a 2-week period, lower $\mathrm{Pr}$ causes $\mathrm{NO}$ to descend about $5 \mathrm{~km}$ lower in altitude. However, as we will discuss below, our uppermesospheric transport is already fairly rapid, and decreasing $\operatorname{Pr}$ would likely worsen our agreement with SOFIE.

As in the previous studies referred to above, the nudging is applied to the WACCMX winds and temperatures but not the trace constituents. As we will show, this means that simply because the large-scale dynamical fields are identical in the model and the analysis, it does not guarantee that the tracer fields in WACCMX will respond identically to that given by NAVGEM. The model was started on 1 December from stabilized initial conditions generated by a previous run. The tracers are thus initialized at that time. Nitric oxide in the model is generated using the same auroral electron pattern used by Pedatella et al. (2018), namely, a fixed characteristic energy of $2 \mathrm{keV}$.

\subsection{NAVGEM-HA}

To constrain WACCMX dynamical fields, we use a meteorological analysis of winds, temperatures, and constituents from a high-altitude version of NAVGEM-HA. NAVGEMHA is the middle-atmospheric extension of the Navy's operational weather forecast system (Hogan et al., 2014). Details of the high-altitude extension are provided by Eckermann et al. (2018), McCormack et al. (2017), and Hoppel et al. (2013). Briefly, to supplement the operational tropospheric and stratospheric observations used in the operational forecast system, middle-atmosphere conditions in NAVGEM-HA are constrained by the additional assimilation of three satellite datasets. These include (1) Microwave Limb Sounder (MLS) temperature, ozone, and water vapor (Schwartz et al., 2008), (2) temperature profiles from the Sounding of the Atmosphere using Broadband Emission Radiometry (SABER) (Remsberg et al., 2008; Rezac et al., 2015), and (3) microwave radiances from the upperatmosphere sounding channels of the Special Sensor Microwave Imager/Sounder (SSMIS) on the Defense Meteorological Satellite Program (DMSP) platforms (Swadley et al., 2008). Synoptic analyses of horizontal winds and temperatures are produced at a 6-hourly cadence and are used to initialize short-term forecasts, ultimately producing a 3 hourly analysis/forecast product each day up to $\approx 100 \mathrm{~km}$. Validation of NAVGEM-HA wind fields against independent ground-based wind measurements have been provided by 
McCormack et al. (2017), Eckermann et al. (2018), and Jones et al. (2020). Also, the tides derived from these winds have been compared with independent satellite (Dhadly et al., 2018) and ground-based data (Stober et al., 2020). Finally, Eckermann et al. (2018) successfully compared NAVGEMHA temperatures against AIM SOFIE data. However, a comparison of NAVGEM-HA tracer (i.e., $\mathrm{H}_{2} \mathrm{O}$ ) analyses with independent observations has not yet been published; this will be provided in Sect. 3 below.

\section{Model results}

Our baseline comparisons are shown in Figs. 1-4, which present model results that can be compared with previously published observations and simulations for the 2013 event. Figure 1 is a comparison of SOFIE $\mathrm{NO}$ and $\mathrm{H}_{2} \mathrm{O}$ data with calculated WACCMX results for the first 3 months of 2013. A similar figure of SOFIE data was first published by Bailey et al. (2014; see their Fig. 1), although here, in order to facilitate subsequent model comparisons, we show the SOFIE data on a pressure grid. Figure 1 shows zonal and daily averages of the SOFIE observations and of the corresponding model output at the local times and locations of the SOFIE occultations (i.e., local sunset, spacecraft sunrise). As we shall see, there is considerable longitudinal variability in the data. This means that a zonal average $\mathrm{NO}$ value equal to, for example, 100-200 ppbv actually reflects longitude sectors where much greater values are observed combined with many longitudes where the data were too low to allow for a retrieval. When the data are too low to allow for a retrieval, the mixing ratios are set to $10^{-5} \mathrm{ppbv}$. The top of the left column shows the progression of the occultation latitudes, and the model is sampled at the same latitudes.

As seen in Fig. 1, both observations and model have a tongue of enhanced NO descending downwards during this period. Looking at the detailed time evolution in all four panels, we see that initially the tracer fields are transported upwards in the week immediately after the warming (onset is Day 5 as per Orsolini et al., 2017). This uplift is seen in both the $\mathrm{H}_{2} \mathrm{O}$ and $\mathrm{NO}$ (although perhaps less so in the SOFIE $\mathrm{H}_{2} \mathrm{O}$ for reasons that are not clear; certainly the reduced sensitivity of SOFIE to such low mixing ratios above $80 \mathrm{~km}$ must be considered) and is consistent with similar initial uplifts simulated by Limpasuvan et al. (2016) and Orsolini et al. (2017). Figure 2 shows this more clearly by presenting the time evolution of the daily averaged altitude of the enhanced NO tongue in both WACCMX and SOFIE as defined by the pressure level of the $50 \mathrm{ppbv}$ value. The figure shows that in WACCMX, before the warming, $50 \mathrm{ppbv}$ of NO are present as low as $0.04 \mathrm{hPa}($ about $70 \mathrm{~km})$ and in the week after the onset are brought up to $0.004 \mathrm{hPa}$ (about $84 \mathrm{~km}$ for this date). Then, after about 5-10 d from the SSW, a strong persistent descent begins such that tracer values at $0.004 \mathrm{hPa}$ are brought down to about $0.2 \mathrm{hPa}$ (specifically, $0.18 \mathrm{hPa}$ on our grid) by early February (Day 36). SOFIE shows the same behavior, although the initial uplift appears somewhat more muted. The $50 \mathrm{ppbv}$ marker in SOFIE starts at $0.01 \mathrm{hPa}$, rises to $0.004 \mathrm{hPa}$, and then descends to $0.2 \mathrm{hPa}$ by Day 45 .

Figures 1 and 2 illustrate several points that are relevant for the rest of the paper. First, at least when viewed in the zonal mean, there is no evidence in either SOFIE or WACCMX for significant NO contributions to the middle and lower mesosphere from altitudes above $0.004 \mathrm{hPa}$, and even that pressure just represents air that was temporarily lifted upwards. This is generally consistent with Randall et al. (2001), who concluded that the immediate source region of the enhanced NO seen in the lower mesosphere and stratosphere was from the upper mesosphere and not the thermosphere. We have furthermore confirmed that this zonal mean perspective is representative by looking at individual longitudes in both SOFIE and WACCMX output. Thus, in the SOFIE data, peak values of $1000 \mathrm{ppbv}$ or greater are found at $0.004 \mathrm{hPa}$ for specific longitudes in early January, are briefly uplifted to $0.002 \mathrm{hPa}$ before descending, but never descend below $0.02 \mathrm{hPa}$. Likewise in WACCMX, the tongue of descending NO seen in Fig. 1 is essentially peeled off from the bottom side of the NO layer. As a result of this analysis and in the absence of any contribution of $\mathrm{NO}$ from above $0.004 \mathrm{hPa}$, in subsequent discussion, we refer to this as upper-mesospheric NO, not MLT NO.

This is important because while there are clearly differences between SOFIE and WACCMX between 0.004 and $0.001 \mathrm{hPa}$ during this period (see Hendrickx et al., 2018, for more detailed comparisons of WACCM and SOFIE above $90 \mathrm{~km}$ ), it is our assessment that these differences are not relevant to the present study. Second, the generally continuous variation in SOFIE shows no evidence for any production by in situ ionization from energetic electrons, as was observed recently by Duderstadt et al. (2021). Duderstadt et al. suggested that perhaps SOFIE sampled too far poleward to observe effects from radiation belt electrons. In any event, this speaks to a long-standing question about the inability of WACCMX (or just WACCM) to deliver sufficient enhanced NO to the middle atmosphere (cf. Pedatella et al., 2018; Randall et al., 2015); our results suggest that for this event, transport from the $80-85 \mathrm{~km}$ region, not in situ production at lower altitudes, led to the observed NO enhancements. Finally, it is clear that although NO in WACCMX reaches the middle mesosphere about a week earlier than is observed, the descent in WACCMX appears to stall at that point. Thus the WACCMX $50 \mathrm{ppbv}$ isoline reaches $0.18 \mathrm{hPa}$ in early February and then only descends to $0.32 \mathrm{hPa}$ over the course of the next month. By contrast, the observed NO keeps descending continuously and reaches about $0.75 \mathrm{hPa}$. This raises the question as to whether WACCMX can actually deliver upper-mesospheric NO to the upper stratosphere, where it might ultimately be important for ozone chemistry. As we will discuss in subsequent sections of this paper, to 


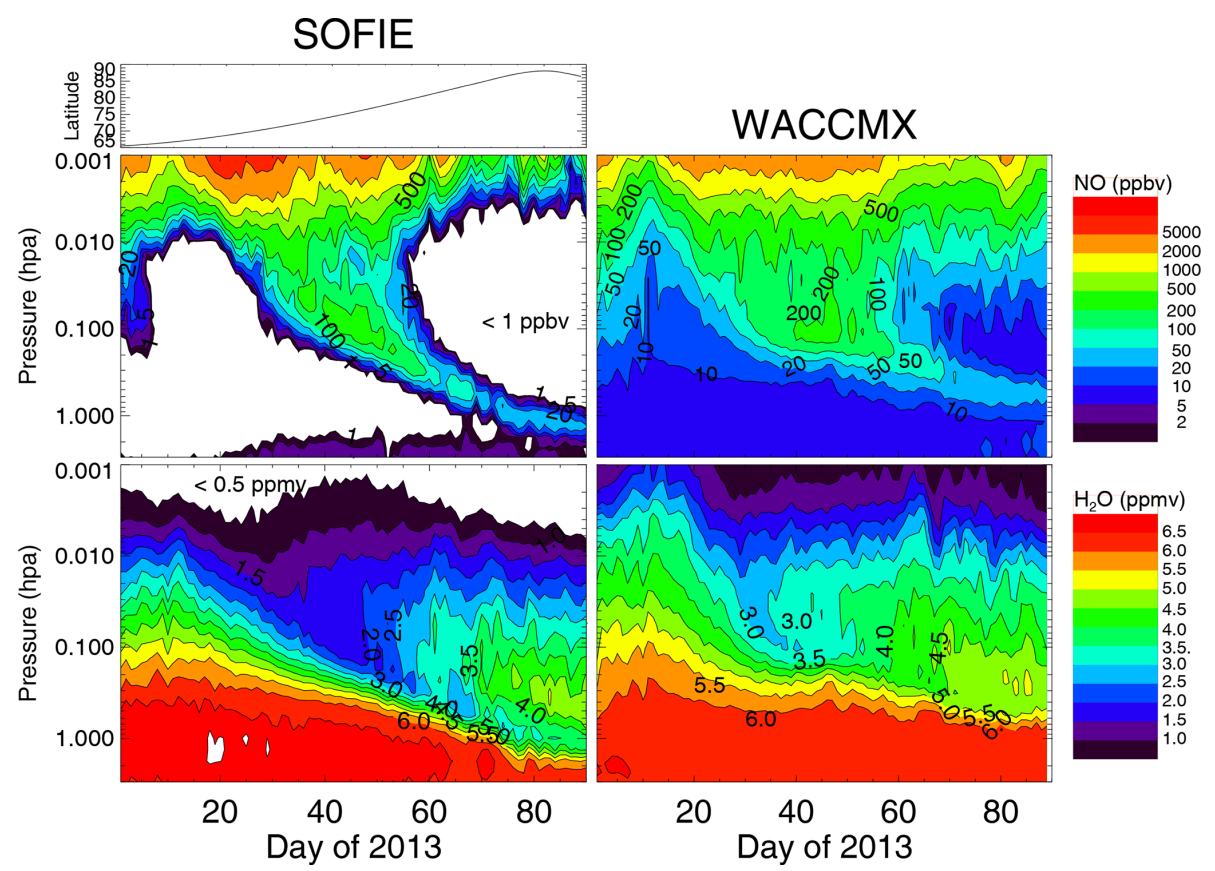

Figure 1. Comparison of the time evolution of daily zonal mean $\mathrm{NO}$ (top color panel, units of ppbv) and $\mathrm{H}_{2} \mathrm{O}$ (bottom, units of ppmv) from SOFIE (left column) and WACCMX (right column) for the first $88 \mathrm{~d}$ of 2013 . The model is sampled according to the latitudes and longitudes tracked by the SOFIE occultation pattern. The latitudinal pattern is shown in the uppermost panel in the left column, going from about $66^{\circ} \mathrm{N}$ on 1 January to about $88^{\circ} \mathrm{N}$ at the March equinox.

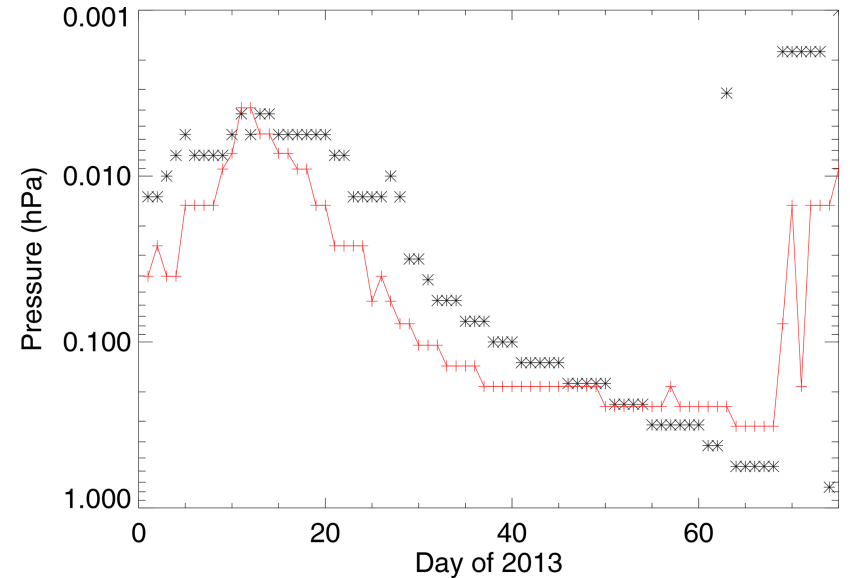

Figure 2. The pressure level of the nitric oxide 50 ppbv value (bottom side of the layer). The pluses connected by a red line are daily values of the WACCMX results shown in Fig. 1. The black stars are the SOFIE data from Fig. 1.

address this question the model-measurement comparison needs to be extended to two and three dimensions.

The differences in descent rate are also seen by tracking the evolution of the vertical profiles of $\mathrm{H}_{2} \mathrm{O}$ from SOFIE, WACCMX, and also the NAVGEM-HA analysis, all sampled at the SOFIE occultation latitudes. This is seen in Fig. 3, which presents zonal average $\mathrm{H}_{2} \mathrm{O}$ profiles for $15 \mathrm{~d}$
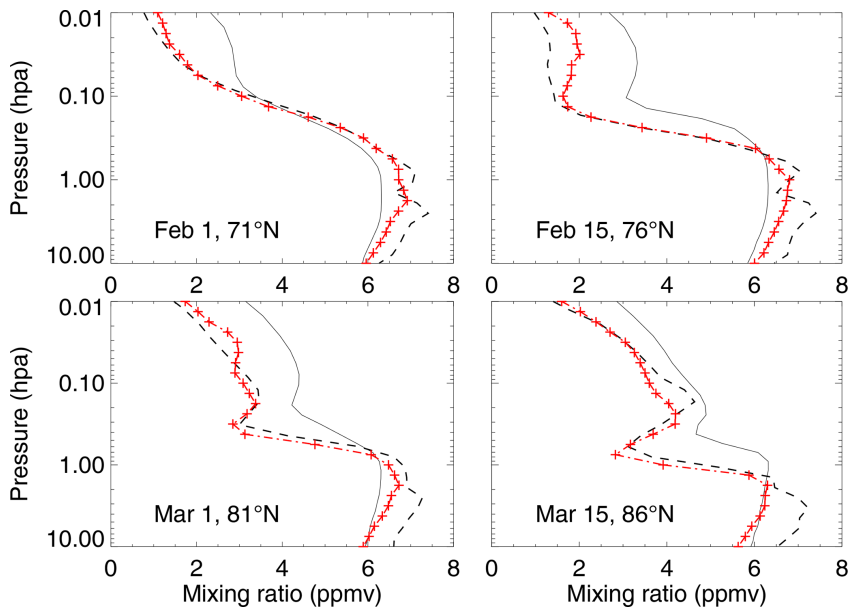

Figure 3. Zonally averaged $\mathrm{H}_{2} \mathrm{O}$ profiles from (solid black) WACCMX calculations, (dashed black) NAVGEM-HA analysis, and (red) SOFIE observations. Both WACCMX and NAVGEM-HA are sampled at the SOFIE occultation latitudes.

intervals from 30 January to 15 March (note: $\mathrm{H}_{2} \mathrm{O}$ fields prior to 30 January were not saved). The good agreement between NAVGEM-HA $\mathrm{H}_{2} \mathrm{O}$ and the independent SOFIE measurements serves as validation of the NAVGEM-HA assimilation of MLS data. Note that WACCMX is only nudged to NAVGEM-HA dynamical fields, not tracer fields, and as noted above, WACCMX was initialized separately 


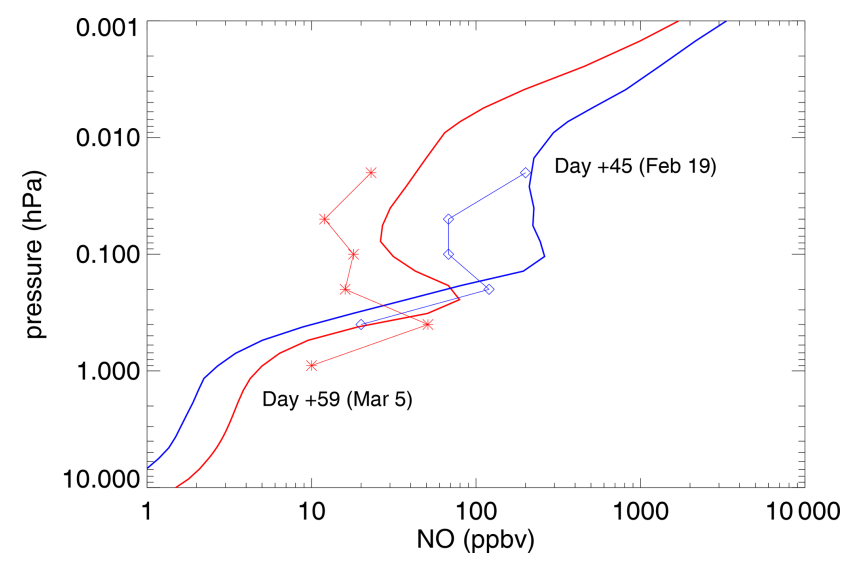

Figure 4. Calculated nitric oxide profiles, averaged from 70 to $90^{\circ} \mathrm{N}$, from WACCMX for the indicated dates to compare with Fig. 3 of Orsolini et al. (2017). The day numbers reflect the convention used by Orsolini et al. and are references to the SSW onset on 5 January (Day 0). The actual dates are shown for reference. The symbols are from the SMR data presented by Oroslini et al. (2017) (red stars for 5 March, blue diamonds for 19 February).

from NAVGEM-HA and SOFIE. Thus the mesospheric $\mathrm{H}_{2} \mathrm{O}$ in WACCMX is consistently higher than SOFIE and NAVGEM-HA. Nonetheless, we see important similarities in the shape of the profiles. On 15 February, the biteout in the WACCMX profile and the local minima in the NAVGEMHA and SOFIE profiles mark the location of the descending mesospheric dry layer at $0.1 \mathrm{hPa}$ seen in Fig. 1. This feature is seen descending in altitude on 1 and 15 March; however, it does not descend equally in WACCMX as compared to the analysis or the data. Thus, in NAVGEM-HA, on $1 \mathrm{March}$, the biteout appears at around $0.3-0.4 \mathrm{hPa}$, while the same feature in WACCMX remains at lower pressure, closer to $0.2 \mathrm{hPa}$. By $15 \mathrm{March}$, the low $\mathrm{H}_{2} \mathrm{O}$ features in the three curves have all descended about a factor of 2 in pressure (to $0.6-0.7$ in SOFIE/NAVGEM and to $0.4 \mathrm{hPa}$ in WACCM), but because NAVGEM-HA and SOFIE were lower in altitude on 1 March, they remain lower in altitude on 15 March. Thus of interest is what happened between 15 February and 15 March that caused WACCMX to differ from the analysis and SOFIE. Another feature of interest is the increase in $\mathrm{H}_{2} \mathrm{O}$ above the biteout. As we will show in the next section, this is likely due to meridional transport.

We conclude this section with our other baseline comparison shown in Fig. 4. This shows high-latitude averaged mixing ratio profiles of NO for two specific dates, 19 February and 5 March, corresponding to the dates given in Fig. 3 of Orsolini et al. (2017) (note that they referenced their profiles by the onset of the SSW on 5 January as Day 0; those day numbers are shown in the figure). They compared WACCM simulations nudged by MERRA with ODIN/SMR data and showed that their calculated NO descent underpredicted the observations by over an order of magnitude. They show the
SMR data as clearly presenting a tongue of enhanced NO descending throughout the period, but their model shows no evidence for such an enhancement. While we do not attempt to make a detailed comparison with the SMR data, we do present a few SMR data points taken from their figure to highlight the point made above, namely, that the WACCMX NO tongue appears to be displaced slightly higher in altitude than what is observed by SMR. Thus, for 19 February, ODIN shows the peak at $0.2 \mathrm{hPa}$; the WACCMX peak is at $0.1 \mathrm{hPa}$. Likewise, on 5 March, ODIN has the peak at $0.4 \mathrm{hPa}$; the WACCMX peak is at $0.2 \mathrm{hPa}$. This appears consistent with the stalling in the WACCMX descent shown in the comparison with SOFIE discussed above.

\section{Two- and three-dimensional patterns of polar tracer descent}

As discussed above, to answer the question as to whether WACCMX is delivering NO to the upper stratosphere, we need to look at the details of the transport in two and three dimensions. Figure 5 shows a series of pressure-latitude contour plots of daily and zonally averaged $\mathrm{H}_{2} \mathrm{O}$ for WACCMX (top row, panels a-d) and NAVGEM-HA (bottom row, panels e-h) at 2-week intervals from 1 February to 15 March. In each panel, two reference lines are indicated. First the vertical dashed lines reflect the latitude of the SOFIE occultation measurement, as previously indicated in Figs. 1 and 3. Second, a reference horizontal line at approximately $0.32 \mathrm{hPa}$ is highlighted; this pressure will be examined more closely in the figures below.

It is immediately clear that in the WACCMX results for February 1 and 15, the strongest descent occurs not at the pole but near $70^{\circ} \mathrm{N}$, i.e., where a noticeable dip in the contour lines is seen. By 1 March, the sub-polar descent in WACCMX has faded and there is a suggestion that the overall descent has noticeably weakened; i.e., the very lowest values of $\mathrm{H}_{2} \mathrm{O}$ have receded upwards somewhat (look at the pressure level associated with the $5.0 \mathrm{ppmv}$ contour). This weakening of the descent may be at least partially consistent with the apparent stalling of the descent we discussed in the previous section. A second reason for this apparent stalling of descent in WACCMX is the sampling. With a positive gradient of model $\mathrm{H}_{2} \mathrm{O}$ going from sub-polar to polar latitudes, as the SOFIE occultation latitudes move to higher latitudes, it will tend to sample model regions with somewhat higher values of $\mathrm{H}_{2} \mathrm{O}$. Thus we see that on 15 February, the SOFIE sampling has moved poleward of the minimum value of the $\mathrm{H}_{2} \mathrm{O}$ in the lower mesosphere. This will also be seen clearly below when we show polar plots.

In the bottom row of Fig. 5 are the corresponding results from NAVGEM-HA. We see both some interesting similarities and differences. What is similar is that NAVGEM-HA does show evidence for off-polar descent on 1 February, and particularly on 15 February. This can be seen in the slope of 


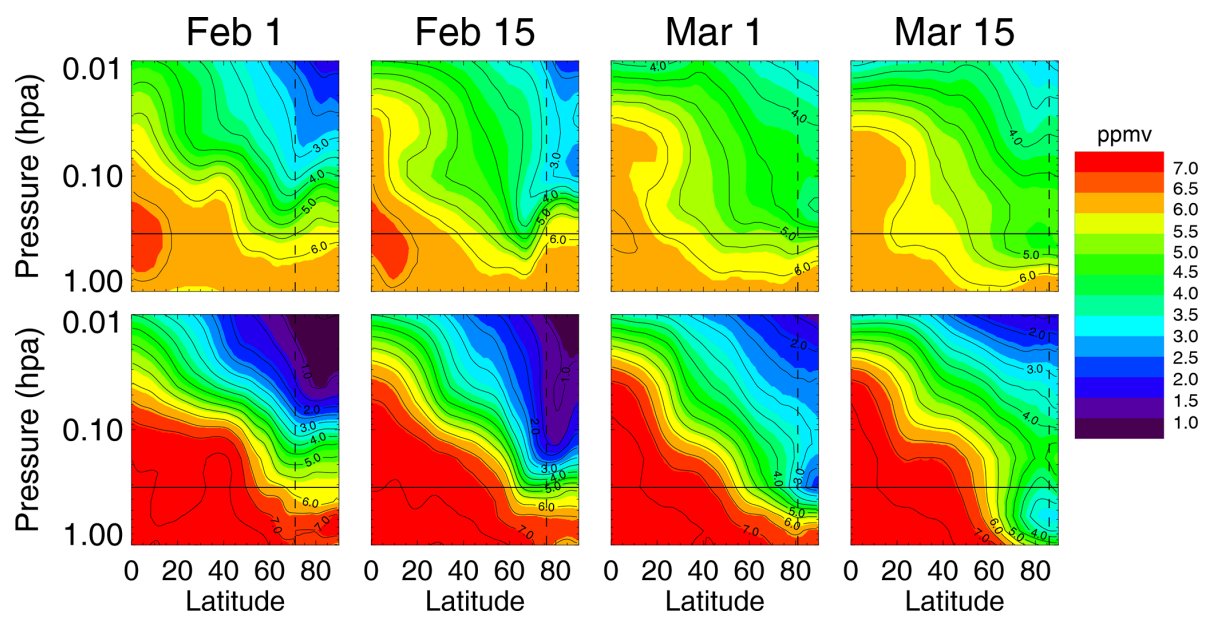

Figure 5. Daily and zonally averaged $\mathrm{H}_{2} \mathrm{O}$ from WACCMX (top row) and NAVGEM-HA (bottom row) for the indicated dates. The horizontal line in each panel is a fiducial to mark the $0.32 \mathrm{hPa}$ level. The vertical dashed lines mark the latitude of the SOFIE occultations for each date.

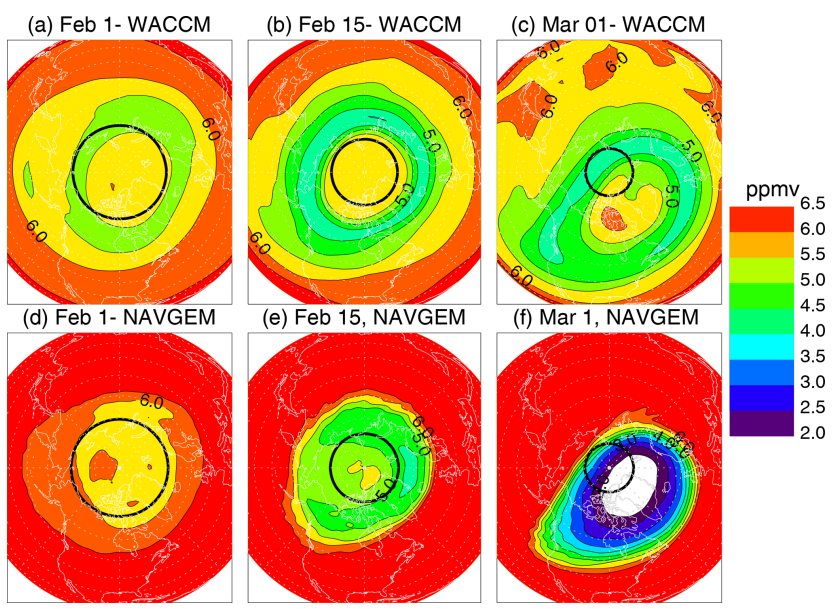

Figure 6. Polar projections at $0.32 \mathrm{hPa}$ of $\mathrm{H}_{2} \mathrm{O}$ from WACCMX (a-c) and NAVGEM-HA (d-f) for the indicated dates. The contour interval is $0.5 \mathrm{ppmv}$. The brightest red is greater than $6.5 \mathrm{ppmv}$, and the white in the NAVGEM-HA field for 1 March represents values less than 2.0 ppmv. The black rings in each panel represent the occultation latitudes for SOFIE for each date. The polar plots are oriented such that a longitude of $90^{\circ} \mathrm{W}$ is at the bottom.

the isolines crossing the $0.32 \mathrm{hPa}$ fiducial line whereby the contour lines show a poleward and upwards tilt from 65 to $85^{\circ} \mathrm{N}$, and thus the minimum value on 15 February is, like WACCMX, near $70^{\circ} \mathrm{N}$. By 1 March, however, all semblance of off-polar descent in the NAVGEM-HA field is gone, and strong pole-centered descent is now quite clear. As we saw in the profile comparison with SOFIE, the tongue of low $\mathrm{H}_{2} \mathrm{O}$ (defined qualitatively by the $4-5 \mathrm{ppmv}$ contour) penetrates down to the $0.4-0.5 \mathrm{hPa}$ level, whereas it remains at $0.2-0.3 \mathrm{hPa}$ in WACCMX. Finally, one area of similarity between NAVGEM-HA and WACCMX is at higher altitudes, between 0.01 and $0.1 \mathrm{hPa}$, where both the analysis and the model show evidence for wetter air moving poleward. Certainly, the absolute values are different, but, as noted above, this may reflect the initialization of WACCMX in December from climatology. The poleward motion evidenced by both the model and the analysis suggests some sort of overturning above the descending air, and this is clearly seen in the NAVGEM-HA analysis by 15 March. This is consistent with the SOFIE data shown in Fig. 1, which shows higher values of $\mathrm{H}_{2} \mathrm{O}$ above the tongues of descending air.

The existence and consequence of off-polar descent, most notably in WACCM but also to some degree in NAVGEM$\mathrm{HA}$ as well, can be dramatically visualized in the polar plots presented in Fig. 6. These are surfaces of $\mathrm{H}_{2} \mathrm{O}$ mixing ratio, for the first three dates shown in Fig. 5, at the $0.32 \mathrm{hPa}$ level that was shown as a reference line in Fig. 5. Also shown as thick black rings are the SOFIE occultation latitudes for these dates. The off-polar descent is manifested as a ring of circumpolar dry air, with a local mixing ratio maximum centered at the pole. This is present in WACCMX on 1 February and in both WACCMX and NAVGEM-HA on 15 February but dissolves in NAVGEM-HA by 1 March. The effect of the poleward progression of the SOFIE sampling in WACCMX can be seen by the fact that the smaller black ring in the WACCMX 15 February panel completely misses the dry annulus of $\mathrm{H}_{2} \mathrm{O}$ even though the actual value of $\mathrm{H}_{2} \mathrm{O}$ in this annulus is lower on 15 February than on 1 February. Therefore we see that descent has occurred in WACCMX, but the SOFIE sampling completely misses it and continues to sample only air with mixing ratios $>5 \mathrm{ppmv}$ (the yellow colors). This demonstrates the need for care in sampling general circulation models to correspond to occultation data at single latitudes.

By 1 March, the WACCMX and NAVGEM-HA fields are very different. Thus the annulus in WACCMX is still present but displaced such that the local maximum is over northern 

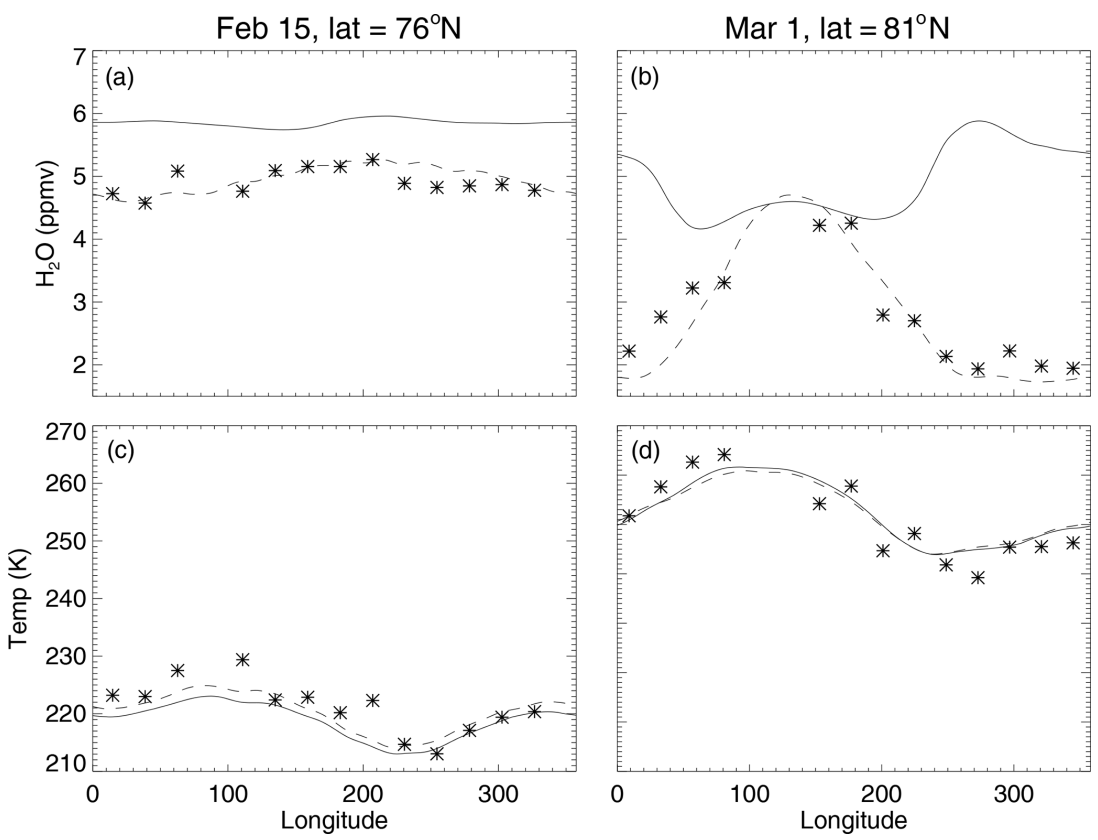

Figure 7. Calculated WACCMX (solid), analyzed NAVGEM-HA (dashed), and observed SOFIE (stars) water vapor (a, b) and temperature (c, d) for $p=0.32 \mathrm{hPa}$ vs. longitude for the indicated dates and latitudes.

Greenland. By contrast, these longitudes are precisely where the deep minimum in NAVGEM-HA $\mathrm{H}_{2} \mathrm{O}$ is seen. The relative phasing of WACCMX and NAVGEM-HA $\mathrm{H}_{2} \mathrm{O}$ and temperature can be most clearly seen in Fig. 7, which presents line plots of the longitudinal variability of these WACCMX and NAVGEM-HA fields and additionally shows the SOFIE data for comparison. On 15 February, in general, all three temperature products agree; there is a small wave with a maximum near $80-100^{\circ} \mathrm{E}$ and a minimum near $220-240^{\circ} \mathrm{E}$. The $\mathrm{H}_{2} \mathrm{O}$ fields all show little variation for this date (the absolute abundance in WACCMX is higher, consistent with what was discussed in regards to Fig. 4). By 1 March, the situation is different. The temperature variation is greater for all three products, and there are some interesting differences in the water vapor variation. The WACCMX field shows a general anticorrelation between the longitudinal variation in $\mathrm{H}_{2} \mathrm{O}$ and temperature, while NAVGEM-HA and SOFIE show a positive correlation. These differences are, at first glance, confusing. In general we would expect the downward advection of dry mesospheric air to be associated with the descending warm stratopause, i.e., an anticorrelation, consistent with observations (Manney et al., 2008). WACCMX conforms to this expectation, but NAVGEM-HA and SOFIE do not and are almost $180^{\circ}$ out of phase - they show the lowest $\mathrm{H}_{2} \mathrm{O}$ corresponding to the coldest temperatures. Here, having the SOFIE data as an independent validation is useful for what otherwise would be a puzzling difference between WACCMX and NAVGEM-HA.

We suggest that the differences between WACCMX and NAVGEM-HA are likely due to differences in the rela- tive roles of vertical and horizontal advection. We can gain some insights into this by looking at the transformed Eulerian mean (TEM) circulations inferred from the WACCMX and NAVGEM-HA wind fields. This can be seen in Fig. 8, which compares the monthly averaged (for February) TEM horizontal and vertical winds calculated from WACCMX and NAVGEM-HA for the mesosphere plotted poleward of $30^{\circ}$ N. Following Siskind et al. (2010), our approach is to directly evaluate the expression (equation 3.5.1a from Andrews et al., 1987)

$\overline{v^{*}}=v-\rho_{o}^{-1}\left(\rho_{o} \overline{v^{\prime} \theta^{\prime}} / \bar{\theta}_{z}\right)_{z}$

and then solve for $\overline{w^{*}}$ from the continuity equation (equation 3.5.2c of Andrews et al., 1987).

Between 0.1 and $0.01 \mathrm{hPa}$, both WACCMX and NAVGEM-HA are in general similar. They both show broad poleward and downward flow. This poleward flow, which is in general well known from previous work (e.g., Smith et al., 2011), explains the increase in $\mathrm{H}_{2} \mathrm{O}$ at these altitudes noted above as being due to the horizontal advection of wetter air. Between 1.0 and $0.1 \mathrm{hPa}$, the flow weakens in both WACCMX and NAVGEM-HA, and here some important differences emerge. Thus, in WACCMX, the descent becomes very weak poleward of $70^{\circ} \mathrm{N}$, and indeed at around $0.2-0.3 \mathrm{hPa}$ a zero isoline is seen, below which $w^{*}$ is positive, implying ascent. In WACCMX, the only place where descent continues unabated to $1.0 \mathrm{hPa}$ is around $70^{\circ} \mathrm{N}$, which closely coincides with the dry annulus seen in the calculated $\mathrm{H}_{2} \mathrm{O}$ shown in Figs. 5 and 6. Note 
(a) w star,waccm

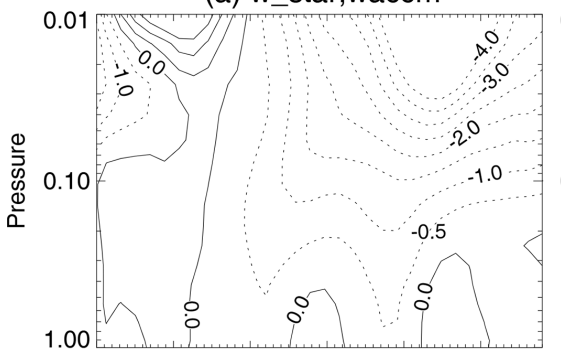

(c) v_star,waccm

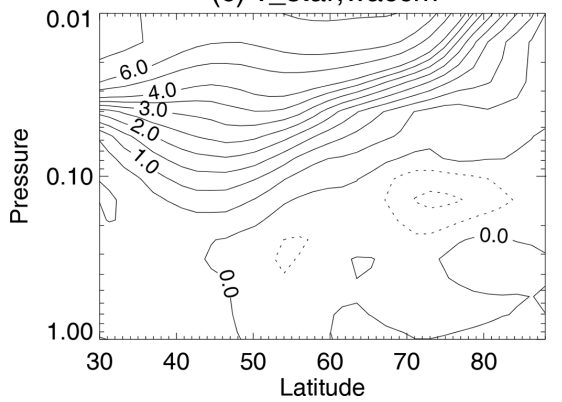

(b) w star,navgem

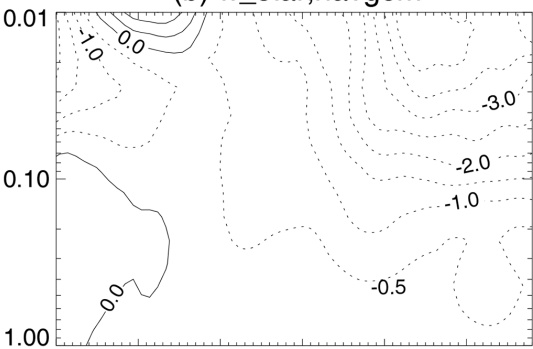

(d) v_star,navgem

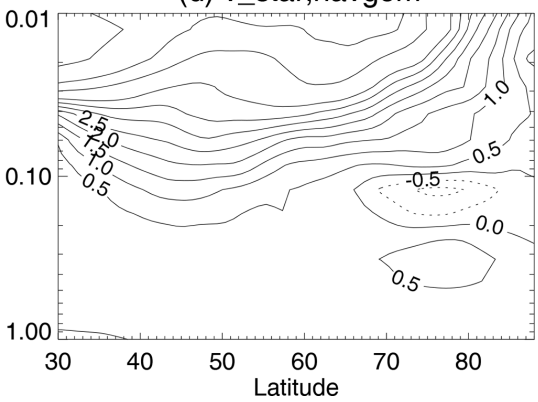

Figure 8. Comparison of monthly mean (February) $w^{*}(\mathbf{a}, \mathbf{b})$ and $v^{*}(\mathbf{c}, \mathbf{d})$ for WACCMX (a, c) and NAVGEM-HA (b, d). For $w^{*}$, the units are $\mathrm{cm} / \mathrm{s}$ with a contour interval of $0.5 \mathrm{~cm} / \mathrm{s}$, and for $v^{*}$, the units are $\mathrm{m} / \mathrm{s}$ and the contour interval is $0.5 \mathrm{~m} / \mathrm{s}$. Negative values are dotted contours.

that when we compare with SOFIE, we must compare at the latitudes of the SOFIE occultation. By late February, as seen in Fig. 1, this is poleward of $75^{\circ} \mathrm{N}$. Thus the stalling out of the simulated descent at SOFIE latitudes is consistent with this zero line in the descent. By contrast, in NAVGEM-HA, $w^{*}$ is negative at all altitudes for middle to high latitudes and in the lower mesosphere.

Regarding the meridional flow, between 0.1 and $0.2 \mathrm{hPa}$ poleward of $70^{\circ} \mathrm{N}$, there is a layer of equatorward flow in both WACCMX and NAVGEM-HA. Thus in WACCMX air initially centered over the pole would descend to $0.2 \mathrm{hPa}$, move equatorward, and then continue descending at $70^{\circ} \mathrm{N}$. This would produce the annular patterns. However, below $0.2 \mathrm{hPa}$, WACCMX and NAVGEM-HA differ. Thus, while at $0.1-0.2 \mathrm{hPa}$ equatorward flow is seen in NAVGEM-HA, at immediately higher pressures, it then reverses such that below $0.3 \mathrm{hPa}$ the flow is poleward again. Thus the $0.3 \mathrm{hPa}$ level, at least in February, appears to be a transition level between off-polar descent reversing to polar-centered descent. As a result, we see the analyzed $\mathrm{H}_{2} \mathrm{O}$ go from a pattern where the minimum values appear as an annulus on 15 February to one where the minimum values are more pole-centered (although offset somewhat towards Greenland).

In general, the residual mean circulation is driven by wave forcing, either from large-scale planetary waves or smallscale gravity waves (Andrews et al., 1987; Smith, 2012). Since the larger-scale forcing is presumably constrained by NAVGEM-HA, any differences in $v^{*}$ and $w^{*}$ between WACCMX and NAVGEM-HA are most likely due to unresolved small-scale gravity waves that are not exactly captured ei- ther by the nudging procedure or by the WACCMX gravity wave parameterization. A truly comprehensive examination of the causes of these differences is beyond the scope of the present study. The differences in the distribution of $\mathrm{H}_{2} \mathrm{O}$ do suggest that nudging to realistic meteorology, while a necessary step, may in and of itself be insufficient to capture the details of mesospheric descent in the polar vortex. Further, as we will discuss in the next section, the persistence of an annular descent pattern in WACCMX complicates the comparison of WACCMX NO and occultation data such as SOFIE. The differences between WACCMX and SOFIE in the $\mathrm{H}_{2} \mathrm{O}$ variation will have analogs in our model-data NO comparison. However, despite these differences, we will show that the overall net transport of NO in WACCMX down to the stratopause is probably not far off from that suggested by the observations.

\section{Delivery of upper-mesospheric NO into the stratosphere}

Here we attempt to evaluate the net deposition of uppermesospheric WACCMX NO${ }_{x}$ into the stratosphere and compare the model with satellite observations. In doing this comparison we must take into account the complex WACCMX tracer descent pattern outlined above, whereby vortexcentered descent appears to encounter a level where $w^{*}$ goes to zero and the descent thus diverges into an annulus. This pattern of descent in WACCMX means that a straightforward comparison of WACCMX with satellite data can be mislead- 

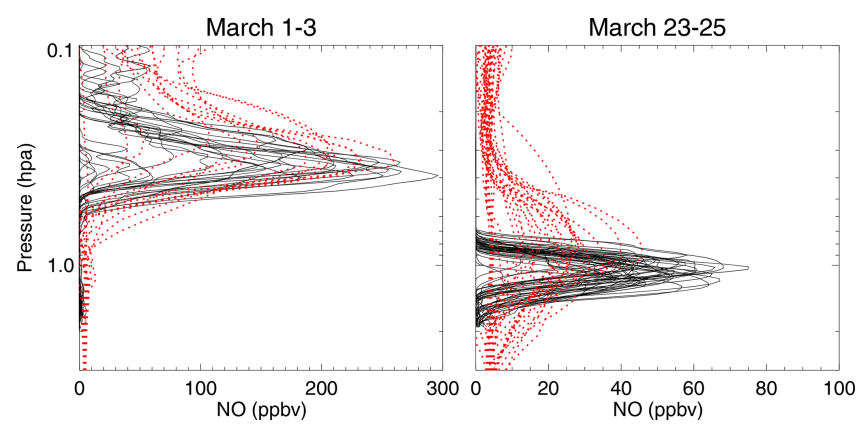

Figure 9. Comparison of nitric oxide data recorded by SOFIE (solid black curves) and ACE (dotted, red) for the two $3 \mathrm{~d}$ periods indicated. For 1-3 March, both instruments are observing near $81^{\circ} \mathrm{N}$; for 23-25 March, SOFIE is observing near $88^{\circ} \mathrm{N}$ and ACE is observing in the range $68-72^{\circ} \mathrm{N}$. The consequences of SOFIE and ACE observing at these different latitudes for the second date range are discussed in the text.

ing. The satellite data that we use to illustrate this are from SOFIE and ACE. ACE is similar to SOFIE in that it is an occultation experiment; however, its orbit differs from AIM, so the latitudinal sampling is different. Bailey et al. (2014, Fig. 1) show the latitudes sampled from both of the experiments. They show that near the beginning of March, they are both sampling near $81^{\circ} \mathrm{N}$ and diverge as the month progresses. We will perform our comparisons for 1-3 March, when ACE and SOFIE were roughly coincident, and also for the period 23-25 March, when ACE was sampling around $68-72^{\circ} \mathrm{N}$ and SOFIE was near the pole $\left(87-88^{\circ} \mathrm{N}\right)$. After this time ACE moved too far south to observe enhanced polar NO.

Figure 9 shows an overall comparison of NO altitude profiles from SOFIE and ACE for the two periods we consider here. Since both instruments are observing the same latitude for 1-3 March, the left panel can be considered the more valid intercomparison. Both data products are provided on a very fine altitude grid ( $1 \mathrm{~km}$ for ACE, $200 \mathrm{~m}$ for SOFIE), and the plot reflects that; however, their native vertical resolutions are coarser and also different for each experiment (3.5 km for ACE and $2.5 \mathrm{~km}$ for SOFIE; Hervig et al., 2019). This appears to show up in the figure, where it seems that the NO layer recorded by SOFIE is narrower and perhaps peaked slightly more sharply than in ACE. With this consideration in mind, the intercomparison for 1-3 March shows good qualitative agreement. For example, both instruments show descent from peaks centered near $0.32 \mathrm{hPa}$ in early March, descending to about $1 \mathrm{hPa}$ for 23-25 March. We will present an additional comparison below using vortex-centered coordinates (equivalent latitudes) which will provide useful additional context for the 23-25 March comparison when the two instruments were not sampling the same latitude.

Figure 10 presents the longitudinal variation of the observations compared with WACCMX, sampled similarly, for two pressure levels, for the beginning of March when ACE

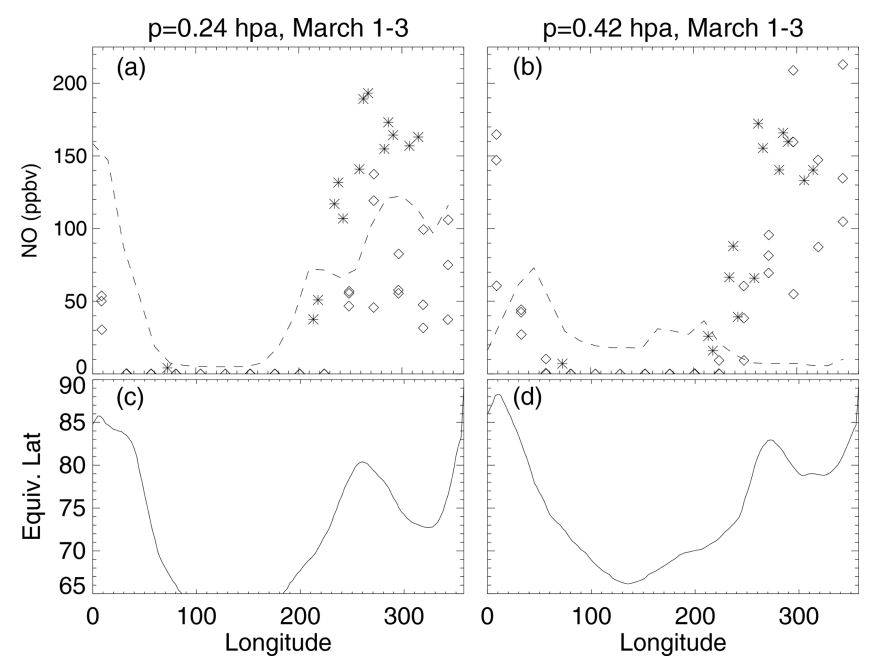

Figure 10. Comparison of WACCMX NO (dashed curve), ACE NO data (stars), and SOFIE NO data (diamonds) vs. longitude. The WACCMX NO output is for 2 March, and the two datasets cover the period 1-3 March. As in Fig. 8, the geographic latitude is $81^{\circ} \mathrm{N}$. Bottom panels show the calculated equivalent latitudes vs. longitude for this geographic latitude.

and AIM are sampling the same latitude. The left panel, $0.24 \mathrm{hPa}$, corresponds to the approximate peak of the WACCMX NO tongue as seen in Figs. 1 and 2. The right panel, $0.42 \mathrm{hPa}$, corresponds to the WACCMX level closest to the approximate peak of the SOFIE and ACE data shown in Fig. 9. It is important to note that both ACE and SOFIE sampled all longitudes; however, at those longitudes where the signal is too low to allow a meaningful retrieval, values of either $10^{-14}$ or negative values are seen in the databases. These appear in the figure as the symbols near zero. Below the model data comparison, we show a dynamical indicator, the equivalent latitude. This is calculated using $3 \mathrm{~d}$ average potential vorticity fields from WACCMX. The averaging in time acted to smooth some of the complex PV spatial structure that occurs in the mesosphere (e.g., Harvey et al., 2009).

The use of equivalent latitude is important because it places the data and the model in a vortex-centered framework. It shows that the equivalent latitude can vary by a significant amount as a function of longitude around a single latitude circle (e.g., see Randall et al., 2002, 2005a). This means that even though ACE and SOFIE are only sampling a single latitude on a given day, they actually are sampling different regions of the vortex. This will be helpful in comparing the satellite data to the model. Both ACE and AIM tend to maximize at equivalent latitudes greater than $75-80$ (i.e., at longitudes less than 30 or greater than 200-220). Note that these are the same longitudes where NAVGEM$\mathrm{HA}$ and SOFIE showed the lowest $\mathrm{H}_{2} \mathrm{O}$ in Fig. 7 - i.e., descent is maximum here. At $0.24 \mathrm{hPa}$, the longitudinal variation in WACCMX NO tends to mirror the observations; however, at $0.42 \mathrm{hPa}$, WACCMX is quite different - show- 
ing minimum $\mathrm{NO}$ at precisely the same longitudes where the observations show maxima. Conversely, it shows elevated NO values at the lower equivalent latitudes where the observations fail to record any data (i.e., longitudes from 80 to 200). This near out-of-phase behavior of the WACCMX $\mathrm{NO}$ is analogous to what was seen in the WACCMX water vapor in Fig. 7. Thus the data show maximal descent with concomitant NO enhancement inside the vortex near 270$330^{\circ} \mathrm{E}$, but the model shows descent away from the vortex core. It is interesting to note that the location of the vortex as shown in Fig. 6 and NO descent maximum as shown here, both near Greenland, is very similar, as observed for other extended SSW events such as in 2004 (Winick et al., 2009) and 2009 (Harvey et al., 2021). We next quantify the overall global, total amount of upper-mesospheric NO that has descended to the upper stratosphere/lower mesosphere (net deposition). To compensate for the detailed differences in WACCMX and the observations, we will use three different approaches. None of these are foolproof; however, taken in aggregate, they show that we can place a general bound on the net deposition upper-mesospheric NO into the lowermesosphere/upper-stratosphere region, despite the fact that the NO enhancement is not necessarily manifest in the same geographic locations in WACCMX as it is in the observations. Figure 11 presents a global polar cap overview of the relevant quantities we used in our analysis. The figure shows polar stereographic views of equivalent latitude, geopotential height, $\mathrm{CH}_{4}$ mixing ratio (ppmv), and $\mathrm{NO}_{x}$ mixing ratio $\left(\log _{10}\right.$, ppbv). Note that Fig. 11 shows $\mathrm{NO}_{x}\left(=\mathrm{NO}+\mathrm{NO}_{2}\right)$, not simply NO as in Figs. 9 and 10. This is because NO has a pronounced diurnal variation whereby it forms $\mathrm{NO}_{2}$ at night and is reformed rapidly each day due to $\mathrm{NO}_{2}$ photolysis at visible wavelengths. On the other hand, $\mathrm{NO}_{x}$ is much longer lived (the discussion regarding Fig. 15 below will quantify this in more detail) and is more useful as a dynamical tracer, as is presented in Fig. 11. During daylight hours, for the pressures shown here, the difference between $\mathrm{NO}$ and $\mathrm{NO}_{x}$ is small $(<5 \%)$, and we have confirmed this by looking both at the $\mathrm{ACE} \mathrm{NO}_{2}$ data (SOFIE does not measure $\mathrm{NO}_{2}$ and so cannot be used for this specific assessment) as well as the WACCM NO and $\mathrm{NO}_{2}$ fields. Thus when we evaluate the total WACCMX budget of $\mathrm{NO}_{x}$, this will differ little from the total NO budget. Finally, in all panels, the thick black line indicates the vortex edge as defined by the method described by Harvey et al. (2002), which identifies the streamfunction contour coincident with the polar night jet at each altitude. Note that the vortex edge is not precisely aligned with an equivalent latitude contour since streamfunction and potential vorticity contours (used for equivalent latitude) are not absolutely parallel.

One of our approaches to quantifying net descent will be vortex centered, i.e., how much WACCMX $\mathrm{NO}_{x}$ is contained inside the polar vortex defined by the black line. A second approach will account for the fact that, as seen in Fig. 9 and evident here, the variation of calculated $\mathrm{NO}_{x}$ does not always appear well correlated with the location of the vortex. Thus, at $0.24 \mathrm{hPa}$, while the enhanced $\mathrm{NO}_{x}$ is generally entrained inside the vortex, the crescent-shaped distribution of the values greater than $100 \mathrm{ppbv}$ ( 2.0 in the plot) does not correspond to the vortex edge. More dramatically, at $0.42 \mathrm{hPa}$, the model pattern is annular, much as the $\mathrm{H}_{2} \mathrm{O}$ was seen to be in Fig. 5. Further, over western North America at $0.42 \mathrm{hPa}$, where the $65^{\circ}$ equivalent latitude contour is labeled, we see enhanced $\mathrm{NO}_{x}$ (green values exceeding 1.4, i.e., mixing ratios greater than $25 \mathrm{ppbv}$ ), extending outside the vortex, to and below $60^{\circ}$ equivalent latitude. This is accompanied by lower values in the vortex core. To attempt to account for this varied dependence of $\mathrm{NO}_{x}$ on equivalent latitude, we will evaluate the amount of WACCMX NO is bounded by different ranges of equivalent latitude. Finally, the third approach will be to use regions of low $\mathrm{CH}_{4}$ as a flag for enhanced $\mathrm{NO}_{x}$. This will also have complications, as we discuss below. These three approaches to quantifying the descending NO in WACCMX will then be compared to a simple geometric model of the latitudinal variation of the NO based upon the SOFIE and ACE data.

A summary of these different results is presented in Table 1, where the total $\mathrm{NO}_{x}$ is expressed in gigamoles (GM) for the two periods presented in Fig. 9. As shown in Fig. 9 (and also Figs. 1 and 2), the observed NO has descended over the 3-week period considered; the pressure ranges for integrating the column NO in the model are approximately 0.18 $0.42 \mathrm{hPa}$ (about $50-56 \mathrm{~km}$ ) for 1-3 March and $0.42-1.15 \mathrm{hPa}$ (about 43-50 km) for 23-25 March. The result of the first approach, i.e., to simply integrate over all the $\mathrm{NO}_{x}$ in the polar vortex, is presented in column 1 . This approach has the advantage of objectivity, the vortex edge is defined by the appropriate streamfunction gradient, and we adopt that for the area to consider. The problem, as noted above, is that there is evidence, at least at some pressures, that enhanced NO has spilled out of the model vortex. At the same time, we may want to account for the possibility that, with the off-polar descent, enhanced NO may not be present in the vortex core. If we simply integrated all the $\mathrm{NO}_{x}$ molecules over the entire polar vortex, under this scenario, we might be including molecules that were not of upper-mesospheric origin. Use of equivalent latitudes allows us to account for both possibilities. The problem with this approach is that it is hard to define a single objective criterion for which range of equivalent latitudes to use. Thus we select three bands to show the sensitivity of the answer to the different ranges - these are given in columns $2-4$ of the table. In general, the values obtained with this approach are roughly consistent with the vortexonly approach. The third and final approach to estimating the amount of upper-mesospheric NO in WACCMX is to use the anticorrelation between $\mathrm{CH}_{4}$ and upper-mesospheric NO. This has long been used in observational analyses, starting with the Halogen Occultation Experiment (HALOE) data on the UARS satellite (cf. Callis et al., 1996; Siskind and Russell, 1996; Siskind et al., 2000), and relies on the idea that, in 
March 2, .24 hpa

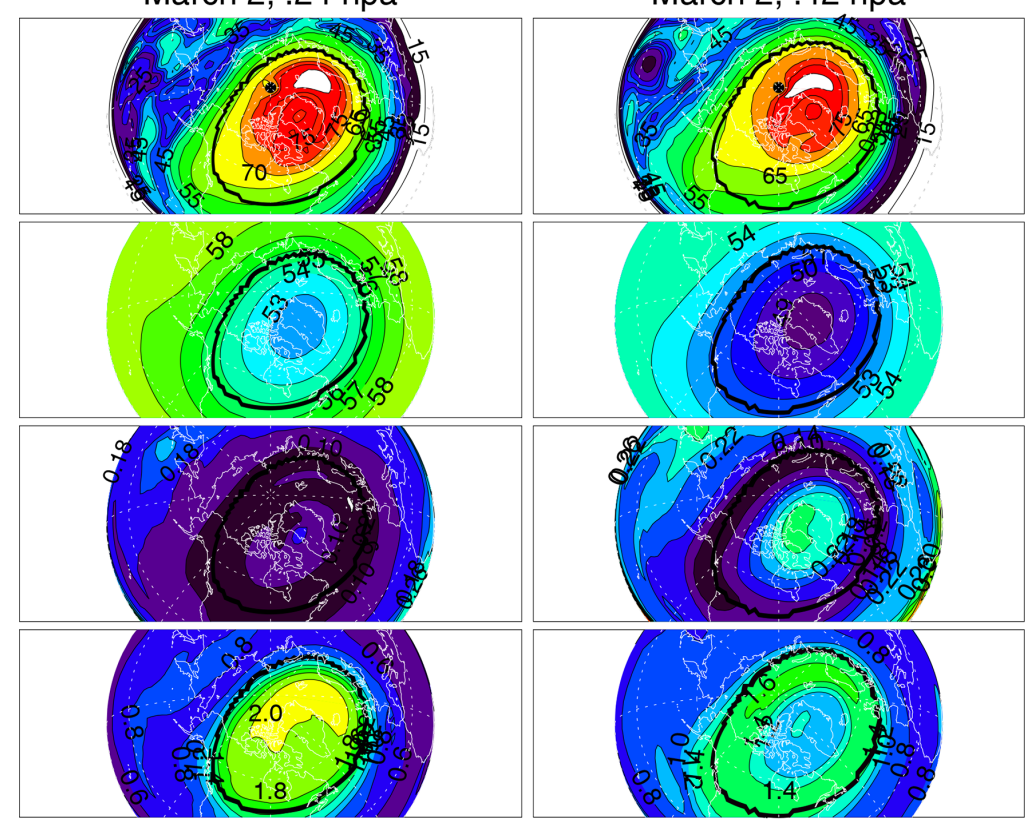

Eq Lat $0^{\circ}$

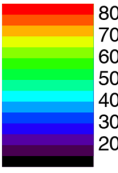

$Z_{\text {geo }}(\mathrm{km})$

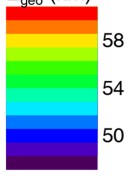

$\mathrm{CH}_{4}$ (ppmv)

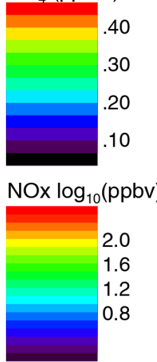

Figure 11. Polar plots of equivalent latitude (top row), geopotential height ( $Z$, second row), $\mathrm{CH}_{4}$ (third row), and $\mathrm{NO}_{x}$ (bottom) from WACCMX. The contour interval is $5^{\circ}$ of latitude for equivalent latitude, $1 \mathrm{~km}$ for $Z$, and $0.2 \log _{10}(\mathrm{ppbv})$ for $\mathrm{NO}_{x}$. The orientations of the maps are such that the center of each map is $80^{\circ} \mathrm{N}, 90^{\circ} \mathrm{W}$.

Table 1. Estimates of MLT NO$x$ deposition in WACCMX and observations (in gigamoles).

\begin{tabular}{|c|c|c|c|c|c|c|c|}
\hline Dates & $\begin{array}{r}\text { Vortex } \\
\text { only }\end{array}$ & $\begin{array}{r}\text { Equiv lat } \\
55-75\end{array}$ & $\begin{array}{r}\text { Equiv lat } \\
60-75\end{array}$ & $\begin{array}{r}\text { Equiv lat } \\
60-80\end{array}$ & $\begin{array}{l}{\text { High } \mathrm{CH}_{4}}^{\text {threshold }}{ }^{\text {a }}\end{array}$ & $\begin{array}{l}\text { Low } \mathrm{CH}_{4} \\
\text { threshold }\end{array}$ & $\begin{array}{r}\text { Geom. } \\
\text { est. }^{\mathrm{c}}\end{array}$ \\
\hline 1-3 March & 0.18 & 0.15 & 0.12 & 0.15 & 0.27 & 0.24 & 0.10 \\
\hline 23-25 March & 0.11 & 0.17 & 0.12 & 0.15 & 0.27 & 0.18 & 0.082 \\
\hline
\end{tabular}

${ }^{\mathrm{a}} \mathrm{CH}_{4}$ threshold is 0.24 ppmv for 1-3 March and 0.3 ppmv for 23-25 March. ${ }^{\mathrm{b}} \mathrm{CH}_{4}$ threshold is 0.12 ppmv for 1-3 March and

$0.24 \mathrm{ppmv}$ for $23-25$ March. $^{\mathrm{c}}$ See text for discussion of uncertainties with this geometric estimate of the observed amount.

general, $\mathrm{CH}_{4}$ and $\mathrm{NO}_{x}$ should be positively correlated in the stratosphere since both are ultimately of tropospheric origin. However, for those situations where air from the upper mesosphere has descended to the stratosphere, $\mathrm{CH}_{4}$ and $\mathrm{NO}_{x}$ will be anticorrelated since upper-mesospheric air is depleted in $\mathrm{CH}_{4}$ but enriched in $\mathrm{NO}_{x}$. With HALOE data, there typically was a single value of $\mathrm{CH}_{4}$ that could be used as a threshold to distinguish between the two air masses (cf. Fig. 4 of Siskind and Russell, 1996). The problem is that in WACCM, the $\mathrm{CH}_{4}-\mathrm{NO}_{x}$ relationship is not necessarily single valued, and the correlation between $\mathrm{CH}_{4}$ and $\mathrm{NO}_{x}$ is often ambiguous.

The complexity of the WACCMX $\mathrm{CH}_{4}$ and $\mathrm{NO}_{x}$ relationship in WACCMX is shown in Fig. 12 for two pressures that correspond to the location of the WACCMX NO layer in Fig. 1 for 1-3 and 23-25 March. The horizontal dotted lines in each panel are possible $\mathrm{CH}_{4}$ thresholds below which the air might be assumed to be of upper-mesospheric origin. The upper threshold includes more values of $\mathrm{CH}_{4}$ to be considered as an indicator of upper-mesospheric air, and thus using this threshold yields larger values of uppermesospheric $\mathrm{NO}_{x}$. The lower threshold is more restrictive. However, no single threshold works very well. For example, the $0.24 \mathrm{ppmv}$ threshold at $0.42 \mathrm{hPa}$ in the $1-3$ March period includes a region near $\mathrm{NO}_{x}$ values of 8-12 ppbv, where $\mathrm{NO}_{x}$ and $\mathrm{CH}_{4}$ appear to be both positively and negatively correlated. Likewise for the 23-25 March period, there is a range of $\mathrm{CH}_{4}$ values associated with $\mathrm{NO}_{x}$ values of 10$12 \mathrm{ppbv}$ with no clear slope. This has the effect of making it unclear whether $\mathrm{NO}_{x}$ values in the range 10-12 ppbv are truly of upper-mesospheric or tropospheric origin. Thus using the upper threshold risks including lower-atmospheric air in the estimate for upper-mesospheric $\mathrm{NO}_{x}$, and indeed our estimates with this threshold, shown in column 5 of Table 1, exceed the values from the vortex and equivalent latitude approaches. Funke et al. (2014b) discuss this problem in terms of different air parcels experiencing different photochemical histories, although the examples they discuss have to do with 

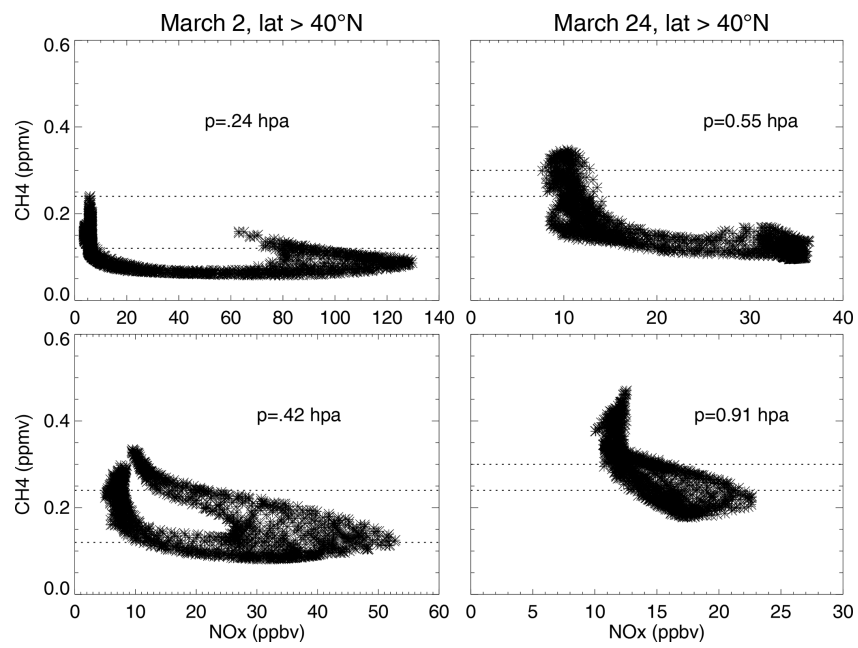

Figure 12. Scatter plot of WACCMX CH 4 vs. $\mathrm{NO}_{x}$ for the indicated model dates and pressures. Note that the vertical range for $\mathrm{CH}_{4}$ is the same for all four panels, but the horizontal ranges for $\mathrm{NO}_{x}$ differ and are labeled separately for each panel. The horizontal dotted lines in each panel are $\mathrm{CH}_{4}$ thresholds that are used to identify MLT $\mathrm{NO}_{x}$; see text for discussion.

seasonal effects that should be less important here. Regardless of the cause, to illustrate the sensitivity of our results, the second more restrictive (i.e., lower) threshold for $\mathrm{CH}_{4}$ yields an integrated upper-mesospheric $\mathrm{NO}$ abundance that is lower and closer to the values obtained using equivalent latitude criteria. This is given in the sixth column of Table 1. Overall, our model estimates agree with the general range given by Funke et al. (2014a), especially if one recognizes that for several of the years in which they get larger values than we show in Table 1 (e.g., 2008) much of the transport occurs in the earlier part of the winter that we do not evaluate here.

The various model-derived global $\mathrm{NO}_{x}$ values in Table 1 can be compared with our geometric model estimates for the two periods that are, in turn, compared with ACE and SOFIE data. Our geometric approach to estimate the uppermesospheric NO abundance implied by the observations is different than with the model since we do not have complete global coverage. However, we can make some plausible estimates by looking at the variation of ACE and SOFIE data with equivalent latitude. This is shown in Fig. 13. The data in the left column can be compared to the WACCMX data seen in Figs. 10 and 11. The data in the right column can be compared with Fig. 14, which shows model results for 23-25 March for the three pressures which roughly bracket the enhanced NO in WACCMX seen in Fig. 1. In general, for both dates, it appears that the measurements do not spread to such low equivalent latitudes as suggested by the model. Whereas Fig. 11 indicated the presence of uppermesospheric $\mathrm{NO}_{x}$ in WACCMX over the western United States at equivalent latitudes of 55-60, the observations for 1-3 March do not record any NO at equivalent latitudes less than about $73^{\circ}$ for this period (note that both AIM and SOFIE were taking samples at these locations, but if the signal is too low for a good retrieval, they will report near-zero values in their databases). Likewise for the 23-25 March period, Fig. 14 shows that the model NO often maximizes at equivalent latitudes between 65 and $70^{\circ}$, while the data show clear falloffs for equivalent latitudes less than 70 . Our specific approach to estimating how much NO might be consistent with the observations is to make the very simple assumption that it is constant as per the horizontal lines in the figure, over the indicated range of equivalent latitudes (i.e., down to $73^{\circ} \mathrm{N}$ for 1-3 March and $70^{\circ} \mathrm{N}$ for 23-35 March), for a $5 \mathrm{~km}$-thick layer. The resulting estimates from this approach are given in the last column of Table 1. It is interesting that our estimates are on the same order as, albeit perhaps a factor of 1.5-2 lower than, our estimates from the model.

The advantage of this approach is that it is ultimately based upon simple geometry, and potential uncertainties can be readily assessed. The two main uncertainties we address are the actual thickness of the layer and its latitudinal (specifically, equatorward) extent. Regarding the thickness of the enhanced NO layer, the data suggest that the layer is narrow and near the limit of the vertical resolution of both the satellites and WACCMX (recall WACCMX gridding corresponds to about $2 \mathrm{~km}$ resolution near the stratopause). With our geometric approach, we can easily scale our answers. Thus if the layer were actually $6 \mathrm{~km}$ thick, our estimates would be low by $20 \%$; if the layer were $4 \mathrm{~km}$ thick, our estimates might be equivalently too high. Regarding the latitudinal extent, this is probably the larger uncertainty since the area of the globe increases as one moves equatorward. If we were to assume that $20 \mathrm{ppbv}$ of $\mathrm{NO}$ extended to equivalent latitudes as low as $61^{\circ} \mathrm{N}$, this would double our estimated value for 23-25 March and would bring it more to the middle of the model estimates. Enhanced NO at such low equivalent latitudes does not appear to be present in the data, and thus we give an approximate upper limit of a factor of 2 for the accuracy of our estimates.

Ultimately, all these comparisons and indirect approaches reinforce the same point, namely, that upper-mesospheric NO (or $\mathrm{NO}_{x}$ ) in WACCMX does not present itself at the same altitudes, latitudes, or longitudes as indicated by the SOFIE and ACE data. However, the global totals are quite close. We conclude that WACCMX/NAVGEM-HA represents the $\mathrm{NO}_{x}$ descent to the lower mesosphere/upper stratosphere reasonably well during this period, and no additional source of $\mathrm{NO}_{x}$ is needed to reproduce the total amount of EPP-IE $\mathrm{NO}_{x}$ during this time.

\section{Discussion and conclusions}

We draw two conclusions from our study. The first deals with the two- and three-dimensional morphology of the mesospheric descent. It appears that subtle differences in the resid- 

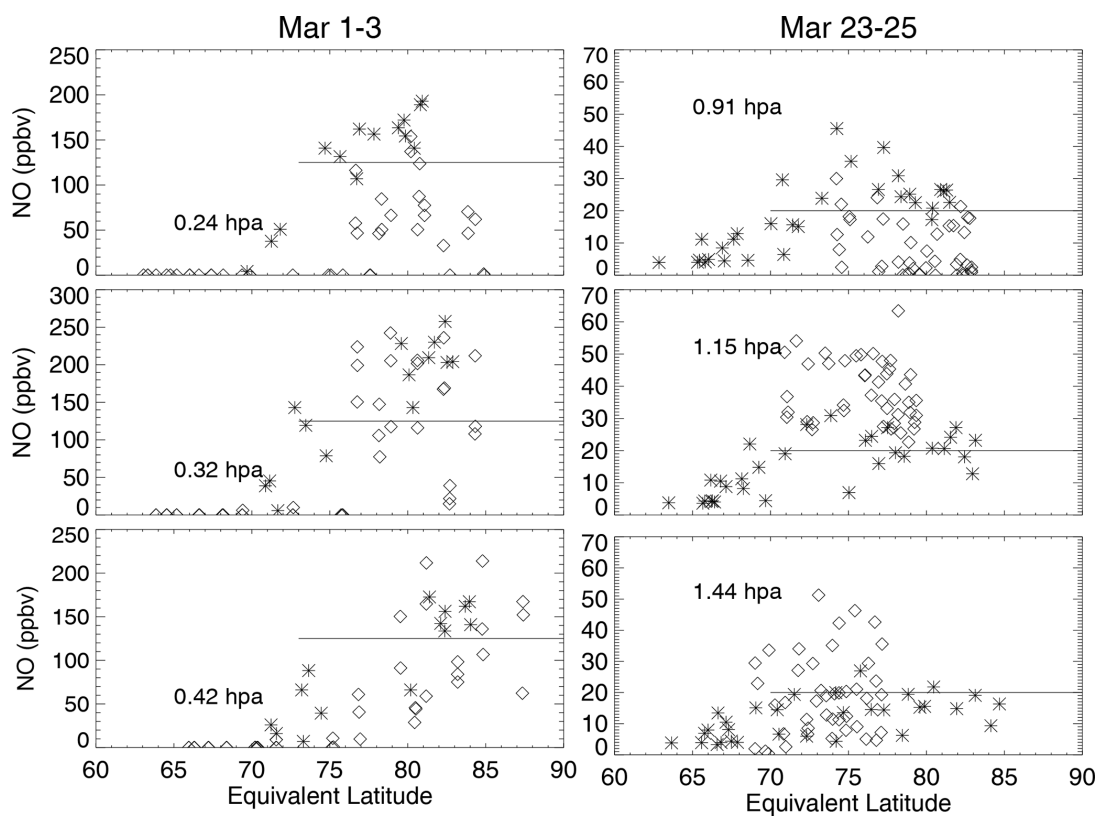

Figure 13. ACE (stars) and SOFIE (diamonds) NO data plotted vs. equivalent latitude for the three pressures near the center of the layer as seen in Fig. 8. The geographic latitude coverage is given in Fig. 8. The horizontal lines in each panel are arbitrary constant values of NO used in a geometric estimate of the global amount of NO that might be consistent with the observations.

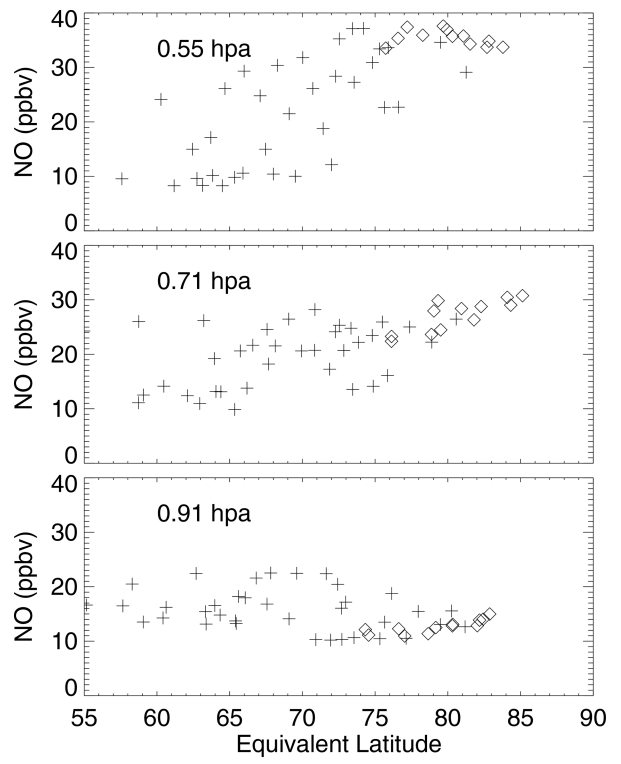

Figure 14. WACCMX NO, sampled according to the SOFIE (diamonds) and ACE (pluses) data shown in the right column in Fig. 12. The pressures differ from those in Fig. 12 due to the fact that the tongue of enhanced NO in WACCMX does not descend as low as is observed (see Fig. 1).

ual mean circulation, presumably due to equivalently subtle differences in gravity wave forcing, can have surprisingly large effects on tracer transport near the stratopause. The existence of off-polar descent was seen many years ago in analyses of the Antarctic polar vortex (Manney et al., 1994); our results here, reflecting the MLS observations assimilated into NAVGEM-HA, provide the first observational support for this morphology at lower mesospheric altitudes. At the same time, it is clear that this effect is overestimated in WACCMX. Another consequence of the differences in tracer transport between WACCMX and observations as discussed in the context of Figs. 8, 13, and 14 is that upper-mesospheric $\mathrm{NO}_{x}$ in WACCMX is advected equatorward more than what ACE and SOFIE suggest. This then could have some consequences for the ability of WACCMX to incorporate uppermesospheric $\mathrm{NO}_{x}$ into the stratospheric $\mathrm{NO}_{x}$ layer, namely, NO may photodissociate too quickly in the model. This is illustrated by Fig. 15, which presents the diurnally averaged lifetime of NO against photodissociation using the parameterization of Minschwaner and Siskind, (1993) as a function of latitude for equinox conditions. It shows that for latitudes equatorward of $70^{\circ} \mathrm{N}$, where much of the NO in WACCMX is found, the lifetime against dissociation is on the order of 2-4 weeks at $1 \mathrm{hPa}$. By contrast, for the regions where the NO in the observations is found, in the vortex core, poleward of $75^{\circ} \mathrm{N}$, the lifetime is much longer - closer to 2-3 months. Nitric oxide here would see much less sunlight than in the model and could continue descending lower into the stratosphere.

Our second main conclusion follows from our earlier study (Siskind et al., 2015) and is that we do not require any added in situ chemical production from energetic electrons below $80-85 \mathrm{~km}$. This conclusion echoes that reached by Shepherd et al. (2014) for the $2006 \mathrm{SSW}$ event. To be fair, this period of 


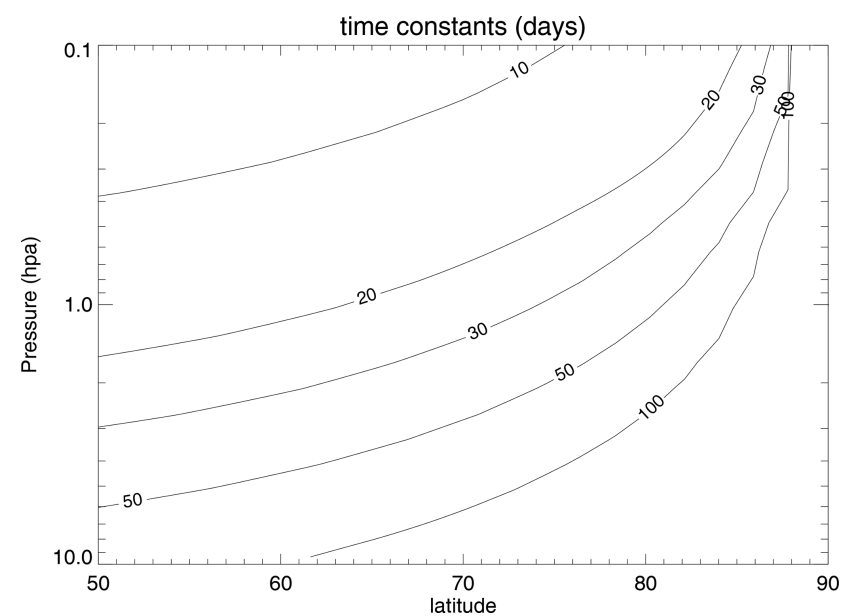

Figure 15. Diurnally averaged time constant against NO photolysis by UV sunlight as a function of latitude and pressure. Equinox conditions are assumed.

time (late winter 2013) appears to not coincide with significant geomagnetic activity. Certainly, for cases with very large heliophysical forcing such as in the Northern winter 20032004 (Randall et al., 2005b) or during solar proton events such as in 2005 (Andersson et al., 2016), the situation is quite different. Our results also may not completely apply to the Southern Hemisphere, where the dynamics are different and NO from EPP effects is routinely seen in the middle stratosphere. However, our results should provide a constraint for models that are used to conduct sensitivity studies of the effects of such ionization. Ultimately, our results continue to point to the need for accurate meteorological analyses which extend into the mesosphere, such as provided by NAVGEMHA.

Code and data availability. The NAVGEM-HA analysis data are available at https://map.nrl.navy.mil/map/pub/nrl/ jgrspace2020/lightspecies/navgem, (last access: $26 \mathrm{Au}-$ gust 2021, US Naval Research Laboratory, 2021), cd to $\mathrm{map} / \mathrm{pub} / \mathrm{nrl} / \mathrm{jgrspace} 2020 /$ lightspecies/navgem. The WACCMX model is open source and available from https://www2.acom.ucar.edu/gcm/waccm (last access: $26 \mathrm{Au}$ gust 2021, NCAR 2021). SOFIE data are available upon request at https://sofie.gats-inc.com (last access: 26 August 2021; SOFIE, 2021). ACE-FTS L2 data are available upon request at https://databace.scisat.ca/l2signup.php (last access: 26 August 2021; ACE/SCISAT, 2021).

Author contributions. DES conceived the study, conducted most of the analysis, and wrote most of the paper, VLH performed the equivalent latitude analysis and edited the sections of the text which described it, FS provided the WACCMX simulations and edited the section which described WACCMX, JPM provided the NAVGEMHA analysis and edited the section which described it, CER eval- uated the present results in the context of past studies of mediumenergy electrons and edited relevant sections of the paper, MEH is the PI of SOFIE and advised on interpretation of the SOFIE retrieval in the mesosphere, and SMB advised on the comparison of SOFIE to the model and helped edit the paper.

Competing interests. The authors declare that they have no conflict of interest.

Disclaimer. Publisher's note: Copernicus Publications remains neutral with regard to jurisdictional claims in published maps and institutional affiliations.

Acknowledgements. We were funded by the NASA Aeronomy of Ice in the Mesosphere explorer program. In addition, Fabrizio Sassi was funded by the Chief of Naval Research, John P. McCormack was funded by the NASA Living with a Star program under interagency agreement NNH13AV95I, and Cora E. Randall was funded by the NSF CEDAR program, grant ACS 1651428.

Financial support. This research has been supported by the National Aeronautics and Space Administration, Goddard Space Flight Center (grant no. Interagency Agreement S50029G).

Review statement. This paper was edited by Bernd Funke and reviewed by two anonymous referees.

\section{References}

ACE/SCISAT: ACE/SCISAT Database, Level 2 Data Access, [data set], available at: https://databace.scisat.ca/12signup.php, last access: 26 August 2021.

Andersson, M. E., Verronen, P. T., Marsh, D. R., Paivarinta, S.-M., and Plane, J. M. C.: WACCM-D Improved modeling of nitric acid and active chlorine during energetic particle precipitation, J. Geophys. Res., 121, 10328-10341, https://doi.org/10.1002/2015JD024173, 2016.

Andrews, D. G., Holton, J. R., and Leovy, C. B.: Middle Atmosphere Dynamics, Academic Press, vol 40 Int'l Geophys Series, 489 pp., 1987.

Bailey, S. M., Thurairajah, B., Randall, C. E., Holt, L., Siskind, D. E., Harvey, V. L., Venkataramani, K., Hervig, M. E., Rong, P. P., and Russell, J. M.: A multi tracer analysis of thermosphere to stratosphere descent triggered by the 2013 stratospheric sudden warming, Geophys. Res. Lett., 41, 5216-5222, https://doi.org/10.1002/2014GL059860, 2014.

Barth, C. A., Tobiska, W. E., Siskind, D. E., and Cleary, D. D.: Solar-terrestrial coupling: Low-latitude thermospheric nitric oxide, Geophys. Res. Lett., 15, 92-94, 1988.

Bernath, P. F., McElroy, C. T., Abrams, M. C., Boone, C. D., Butler, M., Camy-Peyret, C., Carleer, M., Clerbaux, C., Coheur P.-F., Colin,R., DeCola, P., DeMaziere, M., Drummond, J. R., 
Dufour, D., Eveans, W. F. J., Fast, H., Fussen, D., Gilbert, K., Jennings, D. E., Llewellyn, E. J., Lowe, R. P., Mahieu, E., McConnell., J. C., McHugh, M., McLeod, S. D., Michaud, R., Midwinter, C., Nassar, R., Nichitiu, F., Nowlan, C., Rinsland, C. P., Rochon, Y. J., Rowlands, N., Semeniuk, K., Simon, P., Skelton, R., Sloan, J. J., Souch, M.-A., Strong, K., Tremblay, P., Turnbull, D., Walker, K. A., Walkty, I., Wardle, D. A., Wehrle, V., Zander, R., and Zou, J.: Atmospheric chemistry experiment (ACE): mission overview, Geophys. Res. Lett., 32, L15S01, https://doi.org/10.1029/2005GL022386, 2005.

Chandran, A., Collins, R. L., Garcia, R. R., and Marsh, D. R.: A case study of an elevated stratopause generated in the Whole Atmosphere Community Climate Model, Geophys. Res. Lett., 38, L08804, https://doi.org/10.1029/2010GL046566, 2011.

Chandran, A., Collins, R. L., Garcia, R. R., Marsh, D. R., Harvey, V. L., Yue, J., and de la Torre, L.: A climatology of elevated stratopause events in the whole atmosphere community climate model, J. Geophys. Res., 118, 1234-1246, https://doi.org/10.1002/jgrd.50123, 2013.

Dhadly, M. S., Emmert, J. T., Drob, D. P., McCormack, J. P., and Niciejewski, R.: Short-term and interannual variations of migrating diurnal and semidiurnal tides in the mesosphere and lower thermosphere, J. Geophys. Res., 123, 7106-7123, https://doi.org/10.1029/2018JA025748, 2018.

Duderstadt, K. A., Huang, C.-L., Spence, H. E., Smith, S., Blake, J. B., Crew, A. B., Johnson, A. T., Klumpar, D. M., Marsh, D. R., Sample, J. G., Shumko, M., and Vitt, F. M.: Estimating the impacts of radiation belt electrons on atmospheric chemistry using FIREBIRD II and Van Allen Probes observations, J. Geophys. Res., 126, e2020JD033098, https://doi.org/10.1029/2020JD033098, 2021.

Eckermann, S. D., Ma, J., Hoppel, K. W., Kuhl, D. D., Allen, D. R., Doyle, J. A., Viner, K. C., Ruston, B. C., Baker, N. L., Swadley, S. D., Whitcomb, T. R., Reynolds, C. A., Xu, L., Kaifler, N., Kaifler, B., Reid, I. M., Murphy, D. J., and Love, P. T.: High altitude $(0-100 \mathrm{~km})$ global reanalysis system: Description and application to the 2014 Austral Winter of the Deep Propagating Gravity Wave Experiment (DEEPWAVE), Mon. Weather Rev., 2639-2666, https://doi.org/10.1175/MWR-D-17-0386.1, 2018.

Funke, B., Lopez-Puertas, M., Gil-Lopez, S., von Clarmann, T., Stiller, G. P., Fischer, H., and Kellman, S.: Downward transport of upper atmospheric $\mathrm{NO}_{x}$ into the polar stratosphere and lower mesosphere during the Antarctic 2003 and Arctic 2002/2003 winters, J. Geophys. Res, 110, D24308, https://doi.org/10.1029/2005JD006463, 2005.

Funke, B., Lopez-Puertas, M., Holt, L., Randall, C. E., Stiller, G. P., and von Clarmann, T.: Hemispheric distributions and interannual variability of $\mathrm{NO}_{y}$ produced by energetic particle precipation in 2002-2012, J. Geophys. Res., 119, 13565-13582, https://doi.org/10.1002/2014JD022423., 2014a.

Funke, B., Puertas, M.-L., Stiller, G. P., and von Clarmann, T.: Mesospheric and stratospheric $\mathrm{NO}_{y}$ produced by energetic particle precipitation during 2002-2012, J. Geophys. Res., 1994429 4446, https://doi.org/10.1002/2013JD021404, 2014b.

Funke, B., Ball, W., Bender, S., Gardini, A., Harvey, V. L., Lambert, A., López-Puertas, M., Marsh, D. R., Meraner, K., Nieder, H., Päivärinta, S.-M., Pérot, K., Randall, C. E., Reddmann, T., Rozanov, E., Schmidt, H., Seppälä, A., Sinnhuber, M., Sukhodolov, T., Stiller, G. P., Tsvetkova, N. D., Verro- nen, P. T., Versick, S., von Clarmann, T., Walker, K. A., and Yushkov, V.: HEPPA-II model-measurement intercomparison project: EPP indirect effects during the dynamically perturbed NH winter 2008-2009, Atmos. Chem. Phys., 17, 3573-3604, https://doi.org/10.5194/acp-17-3573-2017, 2017.

Gelaro, R., McCarty, W., Suarez, M. J., Todling, R., Moloid, A., Takacs, L., Randles, C. A., Darmenov, A., Bosilovich, M. G., Reichle, R., Wargan, K., Coy, L., Cullather, R., Draper, C., Akella, S., Buchard, V., Conaty, A., Da Silva, A. M., Gu, W., Kim, G.K., Koster, R., Lucchesi, R., Merkova, D., Nielsen, J. E., Partyka, G., Pawson, S., Putman, W., Rienecker, M., Schubert, S. D., Sienkiewicz, M., and Zhao, B.: The Modern Era Retrospective Analysis for Research and Applications, Version 2 (MERRA-2), J. Climate, 30, 5419-5454, https://doi.org/10.1175/JCLI-D-160758.1, 2017.

Gerard, J. C. and Barth, C. A.: High latitude nitric oxide in the lower thermosphere, J. Geophys. Res., 82, 674-680, 1977.

Gordon, E. M., Seppälä, A., and Tamminen, J.: Evidence for energetic particle precipitation and quasi-biennial oscillation modulations of the Antarctic $\mathrm{NO}_{2}$ springtime stratospheric column from OMI observations, Atmos. Chem. Phys., 20, 6259-6271, https://doi.org/10.5194/acp-20-6259-2020, 2020.

Harvey, V. L., Pierce, R. B., Fairlie, T. D., and Hitchman, M. H.: A climatology of stratospheric polar vortices and anticyclones, J. Geophys. Res., 107, 4442, https://doi.org/10.1029/2001JD001471, 2002.

Harvey, V. L., Randall, C. E., and Hitchman, M. H.: Breakdown of potential vorticity-based equivalent latitude as a vortex-centered coordinate in the polar winter mesosphere, J. Geophys. Res., 114, D22015, https://doi.org/10.1029/2009JD012681, 2009.

Harvey, V. L., Datta-Barua S., Wang, N., Pedatella, N. M., Randall, C. E., Siskind, D. E., and Van Caspel, W. E.: NO transport via lagrangian coherent sructures into the top of the polar vortex, J. Geophys. Res., 126, e2020JD034523, https://doi.org/10.1029/2020JD034523, 2021.

Hauchecorne, A., Bertoux, J.-L., Dalaudier, F., Russell, J. M., Mlynczak, M. G., Kyrola, E., and Fussen, D.: Large increase of $\mathrm{NO}_{2}$ in the north polar mesosphere in January-February 2004: Evidence for a dynamical origin from GOMOS, ENVISAT and SABER/TIMED data, Geophys. Res. Lett., 34, L03810, https://doi.org/10.1029/2006GL027628, 2007.

Hendrickx, K., Megner, L., Marsh, D. R., and Smith-Johnsen, C.: Production and transport mechanisms of NO in the polar upper mesosphere and lower thermosphere in observations and models, Atmos. Chem. Phys., 18, 9075-9089, https://doi.org/10.5194/acp-18-9075-2018, 2018.

Hervig, M. E., Marshall, B. T., Bailey, S. M., Siskind, D. E., Russell III, J. M., Bardeen, C. G., Walker, K. A., and Funke, B.: Validation of Solar Occultation for Ice Experiment (SOFIE) nitric oxide measurements, Atmos. Meas. Tech., 12, 3111-3121, https://doi.org/10.5194/amt-12-3111-2019, 2019.

Hogan, T. F., Liu, M., Ridout, J. A., Peng, M. S., Whitcomb, T. R., Ruston, B. C., Reynolds, C. A., Eckermann, S. D., Moskaitis, J. R., Baker, N. L., McCormack, J. P., Viner, K. C., McLay, J. G., Flatau, M. K., Xu, L., Chen, C., and Chang, S. W.: The navy global environmental model, Oceanography, 27, 116-125, https://doi.org/10.5670/oceanog.2014.73, 2014.

Holt, L., Randall, C. E., Peck, E. D., Marsh, D. R., Smith, A. K., and Harvey, V. L.: The influence of major sudden stratospheric 
warming and elevated stratopause events on the effects of energetic particle precipitation in WACCM, J. Geophys. Res., 118, 636-646, 2013.

Hoppel, K. W., Eckermann, S. D., Coy, L., Nedoluha, G. E., and Allen, D. R.: Evaluation of SSMIS upper atmosphere sounding channels for high-altitude data assimilation, Mon. Weather Rev., 141, 3314, https://doi.org/10.1175/MWR-D-13-00003.1, 2013.

Jones, M., Siskind, D. E., Drob, D. P., McCormack, J. P., Emmert, J. T., Dhadly, M. S., Attard, H. E., Mlynczak, M. G., Brown, P. G., Stober, G., Kozlovsky, A., Lester, M., and Jacobi, C.: Coupling from the middle atmosphere to the exobase: Dynamical disturbance effects on light chemical species, J. Geophys. Res., 125, e2020JA028331, https://doi.org/10.1029/2020JA028331, 2020.

Langematz, U. and Tully, M. B., Calvo, N., Dameris, M. de Laat, A. T. J., Klekociuk, A., Muller, R., and Young, P.: Polar Stratospheric Ozone: Past, Present and Future, Chapter 4 in Scientific Assessment of Ozone Depletion, 2018, Global Ozone Research and Monitoring Project-Report No. 58, Geneva Switzerland, 588 pp., 2018.

Limpasuvan, V., Orsolini, Y. J., Chandran, A., Garcia, R. R., and Smith, A. K.: On the composite response of the MLT to major sudden stratospheric warming events with elevated stratopause, J. Geophys. Res., 121, 4518-4537, https://doi.org/10.1002/2015JD024401, 2016.

Manney, G. L., Zurek, R. W., O’Neill, A., and Swinbank, R.: On the motion of air through the stratospheric polar vortex, J. Atmos. Sci., 51, 2973-2994, 1994.

Manney, G. L., Kruger, K., Sabutis, J. L., Sena, S. A., and Pawson, S.: The remarkable 2003-04 winter and other recent warm winters in the Arctic stratosphere since the late 1990's, J. Geophys. Res., 110, D04107, https://doi.org/10.1029/2004JD005367, 2005

Manney, G. L., Daffer, W. H., Strawbridge, K. B., Walker, K. A., Boone, C. D., Bernath, P. F., Kerzenmacher, T., Schwartz, M. J., Strong, K., Sica, R. J., Krüger, K., Pumphrey, H. C., Lambert, A., Santee, M. L., Livesey, N. J., Remsberg, E. E., Mlynczak, M. G., and Russell III, J. R.: The high Arctic in extreme winters: vortex, temperature, and MLS and ACE-FTS trace gas evolution, Atmos. Chem. Phys., 8, 505-522, https://doi.org/10.5194/acp-8505-2008, 2008.

Manney, G. L., Harwood, R. S., MacKenzie, I. A., Minschwaner, K., Allen, D. R., Santee, M. L., Walker, K. A., Hegglin, M. I., Lambert, A., Pumphrey, H. C., Bernath, P. F., Boone, C. D., Schwartz, M. J., Livesey, N. J., Daffer, W. H., and Fuller, R. A.: Satellite observations and modeling of transport in the upper troposphere through the lower mesosphere during the 2006 major stratospheric sudden warming, Atmos. Chem. Phys., 9, 47754795, https://doi.org/10.5194/acp-9-4775-2009, 2009a.

Manney, G. L., Schwartz, M. J., Kruger, K., Santee, M. L, Pawson, S., Lee, J. N., Daffer, W. H., Fuller, R. A., and Livesey, N. J.: Aura Microwave Limb Sounder observations of dynamics and transport during the record-breaking 2009 Arctic stratospheric major warming, Geophys. Res. Lett., 36, L12815, https://doi.org/10.1029/2009GL038586, 2009 b.

Meraner, K., Schmidt H., Manzini, E., Funke, B., and Gardini, A.: Sensitivity of simulated mesospheric transport of nitric oxides to parameterized gravity waves, J. Geophys. Res., 12045-12061, https://doi.org/10.1002/2016JD025012., 2016.
McClandress, C., Scinocca, J. F., Shepherd, T. G., Reader, M. C., and Manney, G. L.: Dynamical control of the mesosphere by orographic and non-orographic wave drag during the extended northern winters of 2006 and 2009, J. Atmos. Sci., 70, 2152 2169, https://doi.org/10.1175/JAS-D-12-0297.1, 2013.

McCormack, J., Hoppel, K., Kuhl, D., de Wit, R., Stober, G., Espy, P., Baker, N., Brown, P., Fritts, D., Jacobi, C., Janches, D., Mitchell, N., Ruston, B., Swadley, S., Viner, K., Whitcomb, T., and Hibbins, R.: Comparison of mesospheric winds from a high-altitude meteorological analysis system and meteor radar observations during the boreal winters of 20092010 and 2012-2013, J. Atmos. Sol.-Terr. Phy., 154, 132-166, https://doi.org/10.1016/j.jastp.2016.12.007, 2017.

Mcdonald, S. E., Sassi, F., Tate, J., McCormack, J. P., Kuhl, D. D., Drob, D. P., Metzler, C., and Mannucci, A. J.: Impact of nonmigrating tides on the low latitude ionosphere during a sudden stratospheric warming event in January 2010, J. Atmos. Sol.-Terr. Phy., 171, 188-200, https://doi.org/10.1016/j.jastp.2017.09.012, 2018.

Minschwaner, K. and Siskind, D. E.: A new calculation of nitric-oxide photolysis in the stratosphere, mesosphere, and lower thermosphere, J. Geophys. Res., 98, 20401-20412, https://https://doi.org/10.1029/93JD02007, 1993.

Natarajan, M., Remsberg, E. E., Deaver, L., and Russell III, J. M.: Anomalously high levels of $\mathrm{NO}_{x}$ in the polar upper stratosphere during April, 2004: Photochemical consistency of HALOE observations, Geophys. Res. Lett., 31, L15115, https://doi.org/10.1029/2004GL020566., 2004.

NCAR: Access to WACCM, available at: https://www2.acom.ucar. edu/gcm/waccm, NCAR, [code], last access: 26 August 2021.

Orsolini, Y. J., Limpasuvan, V., Perot, K., Espy, P., Hibbins, R., Lossow, S., Larsson, K. R., and Murtagh, D.: Modeling the descent of nitric oxide during the elevated stratopause event of January 2013, J. Atmos. Sol.-Terr. Phy., 155, 50-61, https://doi.org/10.1016/j.jastp.2017.01.006, 2017.

Päivärinta, S.-M., Verronen, P. T., Funke, B., Gardini, A., Seppälä, A., and Andersson, M. E.: Transport versus energetic particle precipitation: Northern polar stratospheric $\mathrm{NO}_{x}$ and ozone in January-March 2012, J. Geophys. Res., 121, 6085-6100, https://doi.org/10.1002/2015JD024217, 2016.

Pedatella, N. M., Liu, H.-L., Marsh, D. R., Raeder, K., Anderson, J. L., Chau, J. L., Goncharenko, L. P., and Siddiqui, T. A.: Analysis and hindcast experiments of the 2009 sudden stratospheric warming in WACCMX+DART, J. Geophys. Res., 123, 31313153, https://doi.org/10.1002/2017JA025107, 2018.

Perot, K. and Orsolini, Y. J.: Impact of the major SSWs of February 2018 and January 2019 on the middle atmospheric nitric oxide abundance, J. Atmos. Sol.-Terr. Phy., 218, 105586, https://doi.org/10.1016/j.jastp.2021.105586, 2021.

Pérot, K., Urban, J., and Murtagh, D. P.: Unusually strong nitric oxide descent in the Arctic middle atmosphere in early 2013 as observed by Odin/SMR, Atmos. Chem. Phys., 14, 8009-8015, https://doi.org/10.5194/acp-14-8009-2014, 2014.

Pettit, J. M., Randall, C. E., Peck, E. D., Marsh, D. R., van de Kamp, M., Fang, X., Harvey, V. L., Rodger, C. J., and Funke, B.: Atmospheric efffects of $>30-\mathrm{keV}$ energetic electron precipitation in the Southern Hemisphere winter during 2003, J. Geophys. Res., 124, : 5747-5763, https://doii.org/10.1029/2019JA026868, 2019. 
Randall, C. E., Rusch, D. W., Bevilacqua, R. M., Hoppel, K. W., and Lumpe, J. D.: Polar Ozone and Aerosol Measurement (POAM) II stratospheric $\mathrm{NO}_{2}$, 1993-1996, J. Geophys. Res., 103, 2836138371, 1998.

Randall, C. E., Siskind, D. E., and Bevilacqua, R. M.: Stratospheric $\mathrm{NO}_{x}$ enhancements in the southern hemisphere vortex in winter/spring of 2000, Geophys. Res. Lett., 28, 2385-2388, 2001.

Randall, C. E., Lumpe, J. D., Bevilacqua, R. M., Hoppel, K. W., Fromm, M. D., Salawitch, R. J., Swartz, W. H., Lloyd, S. A., Kyro, E., von der Gathen, P., Claude, H., Davies, J., DeBacker H., Dier, H., Molyneux, M. J., and Sancho, J.: Reconstruction of three-dimensional ozone fields using POAM III during SOLVE, J. Geophys. Res., 107, 8299, https://doi.org/10.1029/2001JD000471., 2002.

Randall, C. E., Harvey, V. L., Manney, G. L., Orsolini, Y., Codrescu, M., Sioris, C., Brohede, S., Haley, C. S., Gordley, L. L., Zawodny, J. M., and Russell III, J. M.: Stratospheric effects of energetic particle precipitation in 2003-2004, Geophys. Res. Lett., 32, L05802, https://doi.org/10.1029/2004GL022003, 2005a.

Randall, C. E., Manney, G. L., Allen, D. R., Bevilacqua, R. M., Hornstein, J., Trepte, C., Lahoz, W., Ajtic, J. V., and Bodeker, G.: Reconstruction and simulation of stratospheric ozone distributions during the 2002 Austral winter, J. Atmos. Sci., 62., 748764, https://doi.org/10.1175/JAS-3336.1, 2005b.

Randall, C. E., Harvey, V. L., Singleton, C. S., Bernath, P. F., Boone, C. D., and Kozyra, J. U.: Enhanced $\mathrm{NO}_{x}$ in 2006 linked to strong Arctic stratospheric vortex, Geophys. Res. Lett., 33, L18811, https://doi.org/10.1029/2006GL027160, 2006.

Randall, C. E., Harvey, V. L., Singleton, C. S., Bailey, S. M., Bernath, P. F., Codrescu, M., Nakajima, H., and Russell III, J. M.: Energetic particle precipitation effects on the southern hemisphere stratosphere in 1992-2005, J. Geophys. Res., 112, D08308, https://doi.org/10.1029/2006JD07696, 2007.

Randall, C. E., Harvey, V. L., Siskind, D. E., France, J., Bernath, P. F., Boone, C. D., and Walker, K. A.: $\mathrm{NO}_{x}$ descent in the Arctic middle atmosphere in early 2009, Geophys. Res. Lett., 36, L18811, https://doi.org/10.1029/2009GL039706, 2009.

Randall, C. E., Harvey, V. L., Holt, L. A., Marsh, D. R., Kinnison, D., Funke B., and Bernath, P. F.: Simulations of energetic particle precipitation effects during the 2003-2004 Arctic winter, J. Geophys. Res., 5035-5048, https://doi.org/10.1002/2015JA021196, 2015.

Remsberg, E. E., Marshall, B. T., Garcia-Comas, M., Krueger, D, Lingenfelser, G. S., Martin-Torres, J., Mlynczak, M. G., Russell III, J. M., Smith, A. K., Zhao, Y., Brown, C., Gordley, L. L., Lopez-Gonzalez, J. J., Lopez-Puertas, M., She, C. Y., Taylor, M. J., and Thompson, R. E.: Assessment of the quality of the version 1.07 temperature-versus-pressure profiles of the middle atmosphere from TIMED/SABER, J. Geophys. Res., 113, D17101, https://doi.org/10.1029/2008JD010013, 2008.

Rezac, A., Kutepov, A., Russell III, J. M., Feofilov, A. G., amd Yue, J.: Simultaneous retrieval of $\mathrm{T}(\mathrm{p})$ and $\mathrm{CO}_{2}$ VMR from two channel non-LTE limb radiances and application to daytime SABER/TIMED measurements, J. Atmos. Sol.-Terr. Phy., 130, 23-42, https://doi.org/10.1016/j.jastp.2015.05.004, 2015.

Rinsland, C. P., Salawitch, R. J., Gunson, M. R., Solomon, S., Zander, R., Mahieu, E., Goldman, A., Newchurch, M. J., Irion, F. W., and Chang, A. Y.: Polar stratospheric descent of $\mathrm{NO}_{y}$ and $\mathrm{CO}$ and Arctic denitrification during winter 1992-1993, J. Geophys. Res., 104, 1847-1861, 1999.

Russell III, J. M., Solomon, S., Gordley, L. L., Remsberg, E. E., and Callis, L. B.: The variability of stratospheric and mesospheric $\mathrm{NO}_{2}$ in the polar night winter observed by LIMS, J. Geophys. Res., 89, 7267-7275, 1984.

Salmi, S.-M., Verronen, P. T., Thölix, L., Kyrölä, E., Backman, L., Karpechko, A. Yu., and Seppälä, A.: Mesosphere-to-stratosphere descent of odd nitrogen in February-March 2009 after sudden stratospheric warming, Atmos. Chem. Phys., 11, 4645-4655, https://doi.org/10.5194/acp-11-4645-2011, 2011.

Sassi, F., and Liu, H.-L., Ma, J., and Garcia, R. R.: The lower thermosphere during the northern winter of 2009: A modeling study using high-altitude data assimilation products in WACCMX, J. Geophys. Res., 118, 8954-8968, https://doi.org/10.1002/jgrd.50632, 2013.

Sassi, F., Siskind, D. E., Tate, J. L., Liu, H.-L., and Randall, C. E.: Simulations of the boreal winter upper mesosphere and lower thermosphere with meteorological specifications in SD-WACCM-X, J. Geophys. Res., 123, 3791-3811, https://doi.org/10.1002/2017JD027782., 2018.

Sassi, F., McCormack, J. P., Tate, J. L., Kuhl, D. D., and Baker, N. L.: Assessing the impact of middle atmosphere observations on day-to-day variability in lower thermospheric winds using WACCMX, J. Atmos. Sol.-Terr. Phy., 212, https://doi.org/10.1016/j.jastp.2020.105486, 2021.

Schwartz, M. J., Lambert, A., Manney, G. L., Read, W. G., Livesey, N. J., Froidevaux, L., Ao, C. O., Bernath, P. F., Booned, C. D., Cofield, R. E., Daffer, W. H., Drouin, B. J., Fetzer, E. J., Fuller, R. A., Jarnot, R. F., Jiang, J. H., Jiang, Y. B., Knosp, B. W., Kruger, K., Li, J.-L., Mlynczak, M. G., Pawson, S., Russell III, J. M., Santee, M. L., Snyder, W. V., Stek, P. C., Thurstans, R. P., Tompkins, A. M., Wagner, P. A., Walker, K. A., Waters, J. W., and Wu, D. L.: Validation of the Aura Microwave Limb Sounder temperature and geopotential height measurements, J. Geophys. Res., 113, D15S11, https://doi.org/10.1029/2007JD008783, 2008.

Seppälä, A., Randall, C. E., Clilverd, M. A., Rozanov, E., and Rodger, C. J.: Geomagnetic activity and polar surface air temperature variablity, J. Geophys. Res., 14, A10312, https://doi.org/10.1029/2008JA014029, 2009.

Shepherd, M. G., Beagley, S. R., and Fomichev, V. I.: Stratospheric warming influence on the mesosphere/lower thermosphere as seen by the extended CMAM, Ann. Geophys., 32, 589-608, https://doi.org/10.5194/angeo-32-589-2014, 2014.

Sinnhuber, M., Friedrich, F., and Bender, S.: The response of mesospheric NO to geomagnetic forcing in 2002-2012 as seen by SCIAMACHY, J. Geophys. Res., 121, 3603-3620, https://doi.org/10.1002/2015JA022284, 2016.

Siskind. D. E., Barth, C. A., Evans, D. S., and Roble, R. G.: The response of thermospheric nitric oxide to an auroral storm 2. Auroral latitudes, J. Geophys. Res., 94, 16899-16911, 1989.

Siskind, D. E., Barth, C. A., and Cleary, D. D.: The possible effect of solar soft $\mathrm{X}$ rays on thermospheric nitric oxide, J. Geophys. Res., 95, 4311-4317, 1990.

Siskind, D. E. and Russell III, J. M.: Coupling between middle and upper atmospheric NO: Constraints from HALOE observations, Geophys. Res. Lett., 23, 137-140, 1996.

Siskind, D. E., Nedoluha, G. E., Randall, C. E., Fromm, M., and Russell III, J. M.: An assessment of Southern Hemi- 
sphere stratospheric $\mathrm{NO}_{x}$ enhancements due to transport from the upper atmosphere, Geophys. Res. Lett., 27, 329-332, https://doi.org/10.1029/1999GL010940, 2000.

Siskind, D. E., Eckermann, S. D., Coy, L., McCormack, J. P., and Randall, C. E.: On recent interannual variability of the Arctic winter mesosphere: Implications for tracer descent, Geophys. Res. Lett., 34, L09806, https://doi.org/10.1029/2007GL029293, 2007.

Siskind, D. E., Eckermann, S. D., McCormack, J. P., Coy, L., Hoppel, K. W., and Baker, N. L.: Case studies of the mesospheric response to minor, major and extended stratospheric warmings, J. Geophys. Res., 115, D00N03, https://doi.org/10.1029/2010JD014114, 2010.

Siskind, D. E., Sassi, F., Randall, C. E., Harvey, V. L., Hervig, M. E., and Bailey, S. M.: Is a high-altitude meteorological analysis necessary to simulate thermosphere-stratosphere coupling?, Geophys. Res. Lett., 42, 8225-8230, doi.10.1002/2015GL065838, 2015.

Smith, A. K., Garcia, R. R., Marsh, D. R., and Richter, J. H.: WACCM simulations of the mean circulation and trace species transport in the winter mesosphere, J. Geophys. Res., 116, D20115, https://doi.org/10.1029/2011JD016083, 2011.

Smith, A. K.: Global dynamics of the MLT, Surv. Geophys., 32, 1177-1230, https://doi.org/10.1007/s10712-012-9196-9, 2012.

SOFIE: SOFIE Database, Level 2 Data Access, [data set] available at: https://sofie.gats-inc.com, last access: 26 August 2021.
Solomon, S., Crutzen, P. J., and Roble, R. G.: Photochemical coupling between the thermosphere and the lower atmosphere 1. Odd nitrogen between 50 to $120 \mathrm{~km}$, J. Geophys. Res., 87, 7206-7220, 1982.

Stober, G., Baumgarten, K., McCormack, J. P., Brown, P., and Czarnecki, J.: Comparative study between ground-based observations and NAVGEM-HA analysis data in the mesosphere and lower thermosphere region, Atmos. Chem. Phys., 20, 11979-12010, https://doi.org/10.5194/acp-20-11979-2020, 2020.

Straub, C., Tschanz, B., Hocke, K., Kämpfer, N., and Smith, A. K.: Transport of mesospheric $\mathrm{H} 2 \mathrm{O}$ during and after the stratospheric sudden warming of January 2010: observation and simulation, Atmos. Chem. Phys., 12, 5413-5427, https://doi.org/10.5194/acp-12-5413-2012, 2012.

Swadley, S. D., Poe, G. A., Bell, W., Hong, Y., Kunkee, D. B., McDermid, I. S., and Leblanc, T.: Analysis and characterization of the SSMIS upper atmosphere sounding channel measurement, IEEE T. Geosci. Remote, 46, 962-983, https://doi.org/10.1109/TGFS.2008.916980, 2008.

US Naval Research Laboratory: Publically Accessible Data Downloads, [data set], available at: https://map.nrl.navy.mil/map/pub/ nrl/jgrspace2020/lightspecies/navgem, last access: 26 August 2021.

Winick, J. R., Wintersteiner, P. P., Picard, R. H., Esplin, D., Mlynczak, M. G., Russell III, J. M., and Gordley, L. L.: OH layer characteristics during unusual boreal winters of 2004 and 2006, J. Geophys. Res., 114, A02303, https://doi.org/10.1029/2008JA013688, 2009. 